\title{
Quantitative risk assessment of fuel preparation room having high-pressure fuel gas supply system for LNG fuelled ship
}

\author{
Byongug Jeong *, Byung Suk Lee, Peilin Zhou
}

Department of Naval Architecture, Ocean and Marine Engineering, University of Strathclyde, 100 Montrose Street, Glasgow, G4 OLZ, UK

*corresponding author; e-mail: byongug.jeong@strath.ac.uk, phone: +44(0)7425694809

\begin{abstract}
This paper systematically investigates the safety of fuel preparation room containing high pressure fuel gas supply systems in order to identify shortcomings and practical gaps of the current regulations. A very large ore carrier of 300,000 DWT was taken as an example and the LNG fuel system was designed for it. An event tree analysis was conducted on the fuel system to identify events that can lead to an explosion. Along with a fault tree analysis model, generic failure data from various sources were used to estimate frequency of potential explosion. For the consequence analysis computational fluid dynamics and finite element analysis software were used to estimate the impact of explosions on the boundary structure of the fuel preparation room. Research findings show that the current rules and regulations concerning the safety of fuel preparation rooms and that the high pressure fuel gas supply system is subject to an unacceptably high level of explosion risk with the frequency of explosion as high as 3.13E-04 per year. The impact of an explosion within the fuel preparation rooms can cause stresses in excess of allowable stress in the bottom structure if not being strengthened. It is proposed that special attention is given to the structural design and/or enhanced safe measures for the FPRs and the relevant regulations updated to account for this.
\end{abstract}

Keywords: risk assessment, LNG-fuelled ship, fuel preparation room, fuel gas supply system, explosion analysis 


\begin{tabular}{ll}
\multicolumn{2}{l}{ List of symbols } \\
$\lambda$ & Failure rate / year \\
$\mathrm{T}$ & Period of time (in year) \\
$\mathrm{Q}_{\mathrm{LR}}$ & Leak rate $(\mathrm{kg} / \mathrm{s})$ \\
$\rho_{\mathrm{L}}$ & LNG density $\left(\mathrm{kg} / \mathrm{m}^{3}\right)$ \\
$\mathrm{A}_{\mathrm{L}}$ & Cross-sectional area of leak $\left(\mathrm{m}^{2}\right)$ \\
$\mathrm{C}_{\mathrm{L}}$ & Discharge coefficient used for liquid $(=0.61)$ \\
$\gamma$ & Specific heat ratio $(=1.31)$ \\
$\mathrm{P}_{\mathrm{S}}$ & Absolute pressure inside pipe $(\mathrm{Pa})$ \\
$\mathrm{P}_{\mathrm{a}}$ & Atmospheric pressure $(\mathrm{Pa})$ \\
$\mathrm{M}$ & Molecular weight $(\mathrm{kg} / \mathrm{kmol})$ \\
$\mathrm{T}_{\mathrm{S}}$ & Storage temperature $(\mathrm{K})$ \\
$\mathrm{R}$ & Universal gas constant $(=8,314)(\mathrm{J} / \mathrm{kmol} \mathrm{K})$ \\
$\mathrm{C}_{\mathrm{G}}$ & Discharge coefficient used for gas $(=0.84)$ \\
$\mathrm{P}_{\mathrm{DI}}$ & Probability of delayed ignition \\
$\mathrm{t}$ & Concerned year $(=1$ year $)$
\end{tabular}

\section{List of acronyms}

BOG boil-off gas

CCC Carriage of Cargoes and Containers

ETA event tree analysis

FGSSs fuel gas supply systems

FSA Formal Safety Assessment

FPR fuel preparation room

HPL high pressure liquid

HPV high pressure vapour

IGF Code International Code of Safety for Ships using Gases or Other Low-flashpoint fuels

KR Korean Register

LEL low explosive level

LPL low pressure liquid

LPV low pressure vapour

VLOCs very large ore carriers 


\section{Introduction}

With the world-wide green shipping movement and consequent introduction of more stringent regulations on engine exhaust emissions, the use of LNG as a marine fuel has become an immediate prospect. Technical advancement in gas engines has also helped in the advent of LNG-fuelled ships (Aymelek et al, 2015). According to a survey on global new-build forecasts, the number of LNG-fuelled ships is anticipated to reach up to 700, accounting for approximately $4.2 \%$ of global newly built ships by 2025 (Lloyd's Register, 2012).

Meanwhile, all ocean-going LNG-fuelled ships having gross tonnage of 500 and above are subjected to International Code of Safety for Ships using Gases or other Low-flashpoint Fuels (IGF Code), which requires the impact of any explosion to be confined to the originating area only, not allowing it to cause disruption of the proper functioning of systems located in other spaces (IMO, 2017). Fuel gas supply systems (FGSSs) with high operating pressure of up to 300 bars have aroused the safety concerns for LNG-fuelled ships (Republic of Korea, 2014; DNV GL, 2014). Nevertheless, the IGF Code, and other related rules and standards have not been able to provide any sufficiently detailed guidelines on designing and arranging the fuel preparation room (FPR) containing high pressure FGSS.

The first ocean-going LNG-fuelled container ship entered service in late 2015. The FPR of this ship is arranged on open deck between two LNG fuel storage tanks (Piellisch, 2013). It is conceivable that any explosion occurring in the FPR can damage the storage tanks and this can lead to a much more serious accident. However, under the current regulations, it appears at least that the boundary structure of the FPR is not specially strengthened in any way.

On larger LNG-fuelled ships, such as very large ore carriers (VLOCs) or container ships over 10,000 TEU it may be necessary to arrange the fuel systems below the freeboard deck, because not only are those too big to be placed on an open deck but also they may be in the way of cargo operation. In this case, an explosion in the FPR can cause more serious damages on the structures around it.

As for the LNG explosion, Filippo (Gavelli, et al., 2011) investigated the impact of vapour cloud explosion during LNG cargo transfer with LNG carriers. Dan (Dan et al., 2014) conducted a risk analysis for LNG-FPSO topside systems. Given the importance on the safety of LNG-fuelled systems, it is not surprising that a variety of studies on the risk of using LNG as a marine fuel have been reported (Germany and Norway, 2012; ADN Administrative Committee, 2014; ABS, 2014). IMO's Sub-committee on Carriage of Cargoes and Containers (CCC) (Republic of Korea, 2014) examined the potential risk of explosion in an FPR containing a high pressure FGSS, and presented the result of computer simulation studies that shows a deterministic impact of an instantaneous explosion with massive concentration of LNG vapour gas, using a CFD code FLACS ${ }^{1}$. Lee (Lee et al., 2015) compared the LNG fire risk of two different types of low pressure FGSS with working pressure of 10 bars.

Despite the requirement of IGF Code, the work exemplified above are mostly limited to the provisions of general guidelines of LNG explosions, and the safety of FPRs with high pressure FGSSs have not been systematically addressed.

1 Flame Acceleration simulator (FLACS), Ver. 10.0, GexCon, Bergen, Norway 
To summarize, due largely to the brevity of its history, the existing regulations, class rules, guidelines and standards appear to have some limitations and gaps. The current regulations do not explicitly state safety requirements of high pressure FGSSs for LNG fuelled ships, and there has been no published work on this issue so far. This was why it was decided to investigate the potential risk levels of explosion in FPRs by means of systematic quantitative risk assessment. It is hoped that the knowledge gained through this study will be able to contribute to enhancing the regulations on designing and arranging FPRs.

\section{Research Methods Used}

In this study the risk levels of FPRs with high pressure FGSSs were investigated. For this work a procedure was devised consisting of four steps based on the IMO's guidelines for Formal Safety Assessment (FSA) (IMO, 2002): accident scenario analysis, frequency analysis, consequence analysis and risk assessment. A flowchart representing the process is shown in Fig. 1.

\subsection{Scenario Analysis}

In the event of a flammable gas developing a leak, an ignition may occur, leading to one of several types of fire. If, on the other hand, the ignition is delayed until after the gas disperses and forms a flammable vapour cloud, then an explosion may occur depending on the level of concentration of the flammable gas (ISO, 2015). Bearing in mind that there are several scenarios and events leading to an explosion, an event tree analysis (ETA) was performed in order to identify all possible routes to explosion, taking into account of the safety systems normally fitted in FPRs.

\subsection{Frequency Analysis}

Frequency analysis is a process of quantifying the probability of unwanted events identified though the scenario analysis. In this step the frequency of initial leak from the FGSS and the probabilities of all possible sequences of events identified in the scenario analysis are estimated. It is to be noted that the current study addresses the risks due to internal events, and not the external events, such as collision or grounding.

Since the history of LNG-fuelled ships is too short for any meaningful statistics to be compiled, this study relies upon appropriate generic data associated with LNG process equipment in offshore and chemical industries. It is inevitable, therefore, that there may be some uncertainties in the results of frequency in the quantitative sense. Nevertheless, this study highlighted the hierarchy of the risk contributor events (Kim et al., 2005).

\subsection{Consequence Analysis}

Consequence analysis consists of two parts: explosion analysis and structural analysis. In the explosion analysis the explosion is simulated using a CFD program and the magnitude of the consequent load on the FPR structure is determined, while in the structural analysis the effect of the load on the structure of the boundary wall of the FPR is assessed by means of an FEA software. 


$$
\mathrm{CH}_{4}+2\left(\mathrm{O}_{2}+3.79 \mathrm{~N}_{2}\right) \rightarrow \mathrm{CO}_{2}+2 \mathrm{H}_{2} \mathrm{O}+7.58 \mathrm{~N}_{2}
$$

The impact of explosion on structures is a function of the ratio of fuel/air mixture and the distance from the ignition point (Versteeg, 2007). However, since the location of the ignition point will be unpredictable and the ratio of fuel/air mixture is determined by various factors such as leak duration, the effectiveness of ventilation system and the time of ignition, it is hard to predict the properties of the explosion precisely. In this context a conservative model to investigate the worst-case will be safer than probabilistic models. Consequently, the explosion was modelled based on complete combustion of the ideal stoichiometric air/fuel ratio equivelent to $17.255 \mathrm{~kg}$ air for each $\mathrm{kg}$ of fuel (Versteeg, 2007). The ignition point was assumed to be $1.0 \mathrm{~m}$ above the floor. This height was selected so as to apply a higher explosion impact load on the floor sturcture (room height is $2.5 \mathrm{~m}$ ). Since LNG is primarily methane $\left(\mathrm{CH}_{4}\right)$ with a small mixture of other hydrocarbons, the composition of the liquid fuel was assumed to be pure methane and the complete combustion equation for this study is given in Eq. (1) (ISO, 2013; Versteeg, 2007).

\subsection{Risk Assessment}

Risk is defined as the product of the probability of occurrence of an accident and its consequence. The consequence is usually expressed in terms of lives lost and injuries caused or financial losses suffered. In the current case, however, there is no direct danger to lives, since the FPR and the areas around it are normally unmanned. The damage to property is difficult to quantify, as it will be case-specific.

For these reasons, it was decided to examine the probability of occurrence of explosion as an item to be compared to the tolerable probability normally accepted by the industry. The consequence can also be examined by studying the stresses that the structure is likely to experience in the event of an explosion and comparing them to the allowable stresses of the material.

\section{A Case Study}

\subsection{Case Ship and Design of the Fuel System}

In order to determine if there is any serious risk in LNG fuel systems a typical ocean-going cargo ship, a 300,000 DWT VLOC, was selected as a case ship for the study. This ship is the subject of 'LNG-Ready Ships"', a joint project between Korean Register (KR) and Hyundai Heavy Industries Co. Ltd. General specifications of the ship including operational profiles are summarised in Table 1.

The main engine was to be modified to a dual fuel engine and the LNG fuel system was designed for this ship in outline in accordance with the IGF Code, class rules and other relevant guidelines in cooperation with $\mathrm{KR}$.

${ }^{2}$ Ships which can be easily retrofitted to use liquefied natural gas (LNG) bunkers. 
It was agreed by all parties concerned that the best arrangement of the LNG fuel system was as represented in Fig. 2. The proposed concept involves transforming No.4 cargo hold into the space for LNG fuel systems, placing the LNG fuel storage tank (IMO Type B Tank), the tank connection space and the FPR inside the same hold (Korean Register, 2015). The load balance on the overall ship's structure and minimum interference to cargo operations were taken into consideration in the decision process. The ship's owner required the capacity of the LNG fuel storage tank to be at least $10,000 \mathrm{~m}^{3}$. The fuel supply to the engine room is through double wall pipes lying on the freeboard deck.

The FPR is $17 \mathrm{~m}$ long, $6 \mathrm{~m}$ wide and $2.5 \mathrm{~m}$ high. Originally the boundary walls of the FPR were designed with no special consideration given to the possible explosion inside. Instead, the general practice of ship structural design in similar cases of withstanding vibration and machinery loads was followed. However, three enhanced designs were also investigated in the consequence analysis.

Fig. 3 shows the conceptual fuel piping system devised for the case ship. The LNG supplied through the bunkering system is stored in the LNG storage tank from where two sets of submersible fuel supply pumps transfer the liquid fuel to FGSS in the FPR. Since IGF Code requires the machinery room to be 'gas-safe', where any single failure is not to lead to fire/explosion, the fuel pipes inside the machinery room are made fully double-walled. On the other hand, if there are two engine rooms, the spaces are regarded as 'ESD-protected'. In this case, if a gas leak is detected, the affected engine room is isolated by ESD system, leaving only the other one operational. For such arrangement double-walled pipes are not necessary. In addition, all confined spaces are fitted with exhaust type mechanical ventilation systems having a minimum capacity of 30 times per hour (IMO, 2017; ABS, 2015).

The concept design of the FGSS was conducted in accordance with the engine maker's specifications and the operational profile of the case ship, as these play a key role in determining the capacity of the FGSS, flow rate, pipe size, position, etc. The diameter of fuel supply line was determined to be $12.5 \mathrm{~mm}$ to meet the required fuel mass flow rate of $2,727.69 \mathrm{~kg} / \mathrm{h}$ for the main engine (MAN Diesel and Turbo). It is to be noted, however, that the pipes of the FGSS are not double walled.

Detailed piping of the FGSS is given in Fig. 4 and the specifications are summarised in Table 2. The FGSS for the main engine consists of a suction drum, HP pumps and a vaporizer. On the other hand, the FGSS for generator engines and auxiliary boiler has a boil-off gas (BOG) heater and compressors in order to adjust the temperature and pressure of the gas fed from the tank before being fed to the combustion systems (MAN Diesel and Turbo, 2013).

The phase and condition of the fuel vary throughout this process, and, as a result, same size leak holes can cause different leak rates depending on their locations. In view of this, the FGSS for the main engine was grouped into three sections: low pressure liquid (LPL), high pressure liquid (HPL) and high pressure vapour (HPV) sections. The FGSS for generator engines and auxiliary boiler was classified as low pressure vapour (LPV). The working pressure used in this study was 5 bars for low-pressure sections and 300 bars for highpressure sections. The temperature of liquid section is $112 \mathrm{~K}$ while vapour section is $318 \mathrm{~K}$ (Republic of Korea, 2014). 


\subsection{Scenario Analysis}

The final outcome of a fuel leak can be diverse, depending on the nature of the leak and functioning of the safety systems. The IGF Code has a mandatory requirement for all FPRs to be equipped with a gas detecting system. In addition, an exhuast type mechnical ventilation system with the capacity of 30 times air change each hour is required to continuously blow the flammable gases out of the space (IMO, 2017; ABS, 2015).

Although all fuel leak may not necessarily lead to a damaging outcome as long as both safety systems function effectively. However, there is a probability of the safety systems malfunctioning. The paths from an initial fuel leak to various final outcomes were identified as shown in an event tree presented in Fig. 5.

From this analysis the types of potential damaging outcomes were identified as fire and explosion. Asphyxiation is another accident outcome, but this was ignored, as it requires presence of a person in the FPR, which is unlikely as the FGSS is remotely controlled and a duty engineer is not normally exposed to a leak event in the room directly.

The gas detector triggers the alarm at $20 \%$ of low explosive level (LEL) of fuel-air mixture, and activate the fuel change-over at $40 \%$ of LEL, shutting down the gas inlet by activating the automatic cut-off valve fitted to the outside of the room and effecting change-over of the fuel system. Therefore, a failure of the gas detector can increase the fuel content in the room to higher than the LEL, leading to a late isolated sceanrio. On the other hand, even when the ventilation is working effectively, a high enough leak rate can lead to explosion scenarios (IMO, 2017).

\subsection{Frequency Analysis}

In this step the frequency of initial leak, probability of safety system failures and probability of immediate/delayed ignition are estimated.

\subsubsection{Initial Leak Frequency}

Since the FGSS is not categorized as a seriously risky section and consequently the pipes are not made double walled, the likelihood of initial leak from the pipes is much higher than in the engine room. The frequency of an initial leak from each equipment described in the conceptual design of FGSS was analysed with respect to three different leak hole sizes: $3 \mathrm{~mm}, 10 \mathrm{~mm}$ and full $(12.5 \mathrm{~mm})$ based on the DNV Leak Frequency Datasheets (DNV, 2012), and the results are summarised in Table 3.

\subsubsection{Probability of Full Leak/Ventilation Failure}

The probability of full leak scenario identified in the ETA is related to the failure of both manual and automatic isolation. The failure of manual isolation is caused by the failure of the gas detector or the alarm system, or the operator not taking or being able to take appropriate action when the alarm sounds, and this leads to the cut-off valve failing to close in time. Where automatic isolation is used, a failure of either leak detector or cut-off valve leads to the failure of the automatic shut-down. In both cases of failure the isolation of the leak is at least prolonged possibly for some time. Since there is no duty engineer constantly present, it is reseaonable to assume that the initial leak is to be detected by a gas detector rather than by a crew member. 
The leaked liquid or gas fuel from a part of the FGSS may vaporize, disperse and be accumulated in the room. The proper operation of the ventilation system can remove the fuel gas from the room or at least reduce the concentration level in the room. A failure of the ventilation system at the time of a leak will make this safety device useless.

The probability of safety system failure are obtained from various sources as showin in Table 4 . The failure rate per year, $\lambda$, was calculated from the upper failure rates shown in the references given in the table. The reliability of each equipment is then estimated using Eq. (2) (Ramiro, 1998).

$$
R(t)=e^{-\lambda t}
$$

Using the reliability data, a fault tree analysis was carried out, as shown in Figs 6 and 7. The result showed that the probability leading to full leak scenario was 0.113 while that of ventilation failure was 0.00126 .

\subsubsection{Probability of Immediate Ignition and Delayed Ignition}

Several models have been developed by the chemical industry to estimate the probability of ignition, but this study adopts DNV model (DNV, 2013) for the probability of immediate ignition as shown in Table 5 as it is widely applied to cases of oil and gas leak.

On the other hand, based on the available OGP models, the "UKOOA - Scenario 22 Offshore Process Gas Congested or Mechanical Vented Module" model was considered to be best suited for LNG leak in FPR in consideration of the propagation of released LNG in a confined space fitted with mechanical ventilation. Table 6 illustrates this model.

Since the probabilities of immediate ignition and delayed ignition are considered to be functions of the leak rate $(\mathrm{kg} / \mathrm{s})$, it is necessary to estimate the leak rate of each scenario. For the liquid leak model, the initial leak rate of LNG can be obtained by Eq. (3) (Crowl, 1990; John, 2010).

$$
\mathrm{Q}_{\mathrm{LR}}=\mathrm{C}_{\mathrm{L}} \mathrm{A}_{\mathrm{L}} \sqrt{2 \rho_{\mathrm{L}}\left(\mathrm{P}_{\mathrm{s}}-\mathrm{P}_{\mathrm{a}}\right)}
$$

For the gas leak model, Eq. (4) defines the pressure Pa. If the ratio of atmospheric pressure to the pipe pressure is greater than the ratio determined by Eq. (4), the flow can be classified as sonic (DNV, 2012).

$$
\left(\frac{\mathrm{P}_{\mathrm{a}}}{\mathrm{P}_{\mathrm{s}}}\right)_{\mathrm{CR}}=\left(\frac{2}{\gamma+1}\right)^{\frac{\gamma}{\gamma-1}}
$$

Based on this, the gas leak model, Eq. (5), adopted semi-ideal gas flow through a convergence-divergence nozzle at sonic regime (DNV, 2012). 


$$
Q_{L R}=C_{G} A_{L} P_{S} \sqrt{\frac{\gamma M}{R T_{S}}\left(\frac{2}{\gamma+1}\right)^{\frac{(\gamma+1)}{(\gamma-1)}}} \quad \text { for } \frac{P_{a}}{P_{s}} \leq\left(\frac{P_{a}}{P_{s}}\right)_{C R}
$$

\subsection{Consequence Analysis}

The impact of an explosion can damage the structure of the FPR in any direction possibly leading to subsequent spread of the accident to other compartments. As shown in Fig. 8, the adjoining spaces of the FPR are a ballast tank, LNG storage tank space, tank connection room, a void space and No.3 and No.5 cargo holds. Although any damage to all the adjoining spaces matters, the LNG fuel storage tank space directly below the FPR is particularly sensitive. Any breach of the storage tank can lead to a far more serious consequence. For this reason the consequence anlysis of this study was focussed on the explosion impact on the bottom wall structure only.

\subsubsection{Impact of Overpressure}

In order to predict the impact of explosion under the condition of complete combustion, this study employed STAR-CCM+, a CFD Code, using the premixed eddy break-up (PEBU) model which solves individual transport equations for mean species on the computational grid, tracking a fuel mass fraction on the grid through the equations. The mean species concentrations are obtained as functions of the mean fuel mass fraction and a one-step global reaction scheme, which is internally calculated based on the unburnt gas composition (CD-adapco, 2014). Since the flow is expected to be turbulent, it uses the Reynolds-averaged Navier-Stokes function with the $\mathrm{k}-\varepsilon$ turbulence model which is compatible with the combustion model (Republic of Korea, 2014).

A series of test simulations was carried out to validate this explosion model. The benchmark used was the results of explosion simulations using FLACS described in an information document submitted to the CCC Sub-committee of IMO (Republic of Korea, 2014). With a gas leak of $5.353 \mathrm{~kg}$ the FLACS simulations predicted a maximum overpressure of 0.27 bars to the nearest wall at $0.75 \mathrm{~m}$ distance from the ignition point, and 3.7 bars for a $41.0 \mathrm{~kg}$ leak. For the test simulations with STAR-CCM+ the geometry of the FPR was built with a transverse 2D axisymmetric formulation. Mass ratios of fuel/air mixture equivalent to the condition used in the FLACS simulations were used. The results of 2D simulations were very close to the FLACS results with deviations of just over $10 \%$ for $5.353 \mathrm{~kg}$ leak and less than $0.3 \%$ for $41.0 \mathrm{~kg}$ leak as summarised in Table 7 .

Fig. 9 shows a 3D model of the conceptual FPR created in SolidWorks, a 3D modelling software, which was then transformed into a 2D axisymmetric model for CFD simulations as illustrated in Fig. 10 and Table 8.

Since the explosion takes place within a very short time period, the leak of the fuel during the process of explosion was ignored. The initial atmospheric pressure and temperature of the FPR were assumed to be $101.3 \mathrm{kPa}$ and $293 \mathrm{~K}$, respectively, and it was also assumed that there was no initial movement of air in the room. In order to investigate the maximum damage of the bottom structure rather than the equipment in the room, the pipes and equipment were not modelled. Numerically, the blast wave is driven by the initial conditions defined in the ignition point at $(0.0,1.0)$, focusing on the magnitude of overpressure imposed on the bottom wall structure which forms a boundary with the LNG storage tank space. The explosion was modelled as a complete combustion with the ideal stoichiometric fuel/air ratio equivelent to 1:17.3 in an attempt to investigate the maximum 
impact of explosion (Versteeg, 2007). The maximum overpressure is observed on the bottom wall at every $0.5 \mathrm{~m}$. For the simulation, an implicit unsteady model was adopted with a very small time step of 1E-7 and the second order accuracy was used for both space and time.

\subsubsection{Structural Analysis}

To assess the structural strength of the FPR with respect to the load produced by a gas explosion, ANSYS 15 was used. The floor of the FPR is a simple stiffened plate as shown in Fig. 11. The primary stiffeners are transverse girders at 3,400 $\mathrm{mm}$ spacing and the deck longitudinals are spaced at $750 \mathrm{~mm}$.

In order to identify the minimum scantlings which can withstand the explosion load obtained from the simulation four different cases were studied using various sizes of primary supporting members, secondary members and the thickness of the base plate. These cases are summarised in Table 9. The girders were designed according to general shipyard practices, where the depth of the web is usually made three times the width of the face plate. It was assumed that all the structural members are made of normal structural steel, as defined by classification rules (DNV, 2015), with the yield strength of $235 \mathrm{~N} / \mathrm{mm}^{2}$. An example modelling of Case 1 is shown in Fig. 12. For the FE analysis, the mesh size was kept at $50 \mathrm{~mm}$ throughout.

\section{Results (Risk Assessment)}

\subsection{Results of Frequency Analysis}

From the frequency analysis using the ETA, the frequency of potential explosion for each case was estimated as shown in Table 10. The overall frequency of explosion is obtained by summing all the cases as illustrated in an FTA of Fig. 13.

The minimum leak rate which can lead to the fuel-air mixture equivalent to the LEL for the given size of the room and the ventilation devices was identified through a simple ventilation simulation (see Appendix 1 for details). From this study it was determined that the explosion scenarios associated with $3 \mathrm{~mm}$ and $10 \mathrm{~mm}$ leak in LPV section, where leak rate is less than $0.07 \mathrm{~kg} / \mathrm{s}$, has little possibility of explosion as long as the ventilation system is effectively working. Therefore, the explosion frequencies associated with these scenarios were set to nil. The overall frequency of explosion was estimated to be $3.13 \mathrm{E}-4$ /year.

Since there are no explicit guidelines for regulating risk levels for LNG-fuelled ships, the impairment frequency limit of 1.00E-4 /year suggested by NORSOKZ-013 was used to judge the acceptability of the explosion frequency (NORSOK, 2001). It is clear that the overall frequency exceeds this limit by a large margin, and the cases associated with the HPL section contributes to this frequency the most.

\subsection{Results of Consequence Analysis}

The spread of overpressure as the explosion progresses can be observed in the flame contours of Fig. 14. The result of the simulation found that the pressure at the ignition point immediately after ignition was 8.4 bars. 
The maximum overpressure on the floor at various transverse distances away from the ignition point obtained from the explosion simulation is summarised in Fig. 15. It can be seen that the maximum overpressure at the centre of the floor is $291 \mathrm{kPa}$ and it decreases as it proceeds away from the centre.

Accordingly the pressure load as shown in Fig. 16 was applied in the structural analysis: $291 \mathrm{KPa}$ from the centre to the $0.5 \mathrm{~m}$ radius, $239 \mathrm{KPa}$ between $0.5 \mathrm{~m}$ and $1.0 \mathrm{~m}$ radius, 166 $\mathrm{KPa}$ between $1.0 \mathrm{~m}$ and $1.5 \mathrm{~m}$ radius, $135 \mathrm{KPa}$ between $1.5 \mathrm{~m}$ and $2.0 \mathrm{~m}$ radius, $96 \mathrm{KPa}$ between $2.0 \mathrm{~m}$ and $2.5 \mathrm{~m}$ radius and $73 \mathrm{KPa}$ between $2.5 \mathrm{~m}$ and $3.0 \mathrm{~m}$ radius.

The results of the FEA are presented in Figs 17 - 19 in the form of shear stress, bending stress and equivalent stress for the four cases.

The maximum stresses to be experienced by the floor of the FPR in the event of an explosion are compared with the allowable stresses specified by the DNV GL Rule (DNV, 2015) as shown in Table 11. It can be seen that all but Case 4 with the highest scantlings fails. This demonstrates that the boundary walls of the FPR must be strengthened considerably if the effects of any potential explosion are to be contained within it.

\section{Sensitivity Analysis}

This study chose an arbitary ignition point to investigate the risk of FPR associated with explosion. Given the fact that the explosion impact much depends on the distance from the ignition point, this generic approach may cause some uncertainties in the results of consequence in a quantitative sense. In addition, the assumption of complete combustion may have resulted in overestimatation of explosion impact for some cases. In this context, a sensitivity analysis was carried out to study the impact for various points of ignition with several cases of methane compositions - about $5 \%$ (air-rich) shown in Eq. (6), $10 \%$ (near complete combustion) and about $15 \%$ (fuel-rich) vol/vol shown in Eq. (7) (Versteeg, 2007). The results are presented in Fig. 20.

Using the results of CFD analysis associated with alternative explosion scenarios, FE analysis was carried out. The results are shown in Table 12 where the regions shaded with red refer to unacceptably high stresses. As expected, the closer the ignition point from the floor, the higher the stress on the bottom structure of FPR was. The near-perfect combustion condition (about $10 \%$ of methane-air ratio) led to higher impact of explosion. In addition, the fuel-rich condition (about $15 \%$ of methane-air ratio) tended to have higher consequences than the fuel-scarce conditoin (about $5 \%$ of matane-air ratio).

$$
\begin{aligned}
& \mathrm{CH}_{4}+2.1 \times 2\left(\mathrm{O}_{2}+3.79 \mathrm{~N}_{2}\right) \rightarrow \mathrm{CO}_{2}+2 \mathrm{H}_{2} \mathrm{O}+2.2 \mathrm{O}_{2}+15.92 \mathrm{~N}_{2} \\
& \mathrm{CH}_{4}+0.7 \times 2\left(\mathrm{O}_{2}+3.79 \mathrm{~N}_{2}\right) \rightarrow \mathrm{CO}_{2}+0.8 \mathrm{H}_{2} \mathrm{O}+1.2 \mathrm{H}_{2}+5.306 \mathrm{~N}_{2}
\end{aligned}
$$

The results of this sensitivity study indicate that the these parameters significanlty affect the impact of potential explosion, implying that the impact of explosion can be mitigated by controlling ignition points and methane-air ratio. 


\section{Discussion}

It was decided from the outset of this study that the results should be applicable to a wide variety of situations and consequently the analyses were conducted on imaginary ships and systems. It was then decided to create a conceptual design of FGSS and use it as the main subject of the study. However, it is quite possible that the leak frquency may have been underestimated because of this, since there will be many more components (e.g. pipes, valves, gauges and so on) in a real FGSS. Nevertheless, similar studies on existing ships and systems can easily be carried out following a similar approach.

For explosion simulations, all obstacles (e.g., heater, pipe, et al) in the room were omitted in the numerical models. In fact, obstacles may play an important role in the overpressure profiles. However, the present study rather set out to enhance the generic understanding of risks associated with this relatively new process and to determine the adequacy of the current provisions in this regard, particularly in determining the safety levels of high pressure FPRs. In real situations, different ships have different arrangements of fuel gas supply systems fitted to FPRs and it is difficult to generalise them in a study such as ours. Moreover, specification of these location-specific parameters, being regarded as subjective variables, is not possible in rules and standards which have to cater for all kinds of situations. In this regard, it was more desirable to take the generic assumption of unrestricted spaces as these will produce more conservative results. On the other hand, as a recommendation for future studies where more specific analysis is required, it will be necessary to conduct case-by-case simulation with actual fuel-air ratio in the subject room by predicting exact leak duration and ignition timing for each case.

In general, the methane content in LNG is about $87 \% \sim 99 \%$ depending on the geographical location of production and the processing methods used. The LNG used in this study was assumed to be pure methane, and this will have introduced slight uncertainty in the results. However, the pure methane case was chosen as the representative case, as it was important for this study to address general situations. In any case the level of this uncertainty cannot be high enough to impair the general conclusions derived from the study and our understanding gained from it. Nevertheless, the sensitivity of LNG compositions on explosion impact needs to be investigated more thoroughly in the future.

A physical explosion due to fast vaporization of a liquid leak could be an additional type of incidents leading to structural damage. One may argue that the risk of this type of incident must also be considered to make the analysis more realistic. However, given the fact that the physical explosion is more likely to occur in large quantity leaks, it is thought that the governing accident would be vapour cloud explosions rather than physical ones, as the FGSS considered here is relatively small with the diameter of the piping system only $12.5 \mathrm{~mm}$.

The hazards caused by the leak or spill of LNG on board a ship are many, including various forms of fire, explosion and cryogenic harm. The FPRs are always unmanned during operation and the risk to human life from cryogenic burns and fire can, therefore, be ruled out. Cryogenic embrittlement of structural materials and fires can cause local problems, but compared to potential damage to human life and the vessel caused by explosions, these are minor. Consequently this study concentrated on explosions. In addition, the effects of various fire accidents and corresponding heat radiation on structure strength are relatively minor compare to the explosion impact and these type of accidents are more likely to be suppressed by fix fire extinguishing systems fitted to FRP before the strucrual damage becomes severe. As an evidence, the IGF Code 4.3 (IMO, 2017) stresses on the limitation of explosion consequences only for in the confined spaces. 


\section{Conclusions}

This paper set out to investigate if the current rules, guidelines and design practices of LNG fuelled ships are adequate. In the process and an exemplary practical procedure to investigating the explosion risk of high pressure FPR was developed and demonstrated by studying the safety of FPRs of a case ship having high pressure FGSS. Results of the risk analysis show that both frequency and consequence of potential explosion are unacceptably high. The findings from the study suggests that FPRs are subject to unacceptably high probability (3.13E-04 per year) of explosion. The consequence analysis revealed that the impact of explosion is severe enough to jeopardise the integrity of the boundary wall structure. From this it can be concluded that the risk is unacceptably high, and thus obviating the necessity for the procedure to evaluate the risk combining the probability and the severity.

Unacceptably high levels of both frequency and consequence of the potential explosion suggest that, at least, either the probability of occurrence of potential explosion is to be reduced by enhancing safety measures in FPR or the structural designs of an FPR is to be substantially enhanced.

Given the fact that the current IGF Code does not specify any safety requirement against the risk of explosion in an LNG-fuelled ship causing damage to other spaces in the ship, it is, therefore, thought that the current study can become a basis for a template for this type of risk analysis, showing that Case 4 with the highest scantlings can be sustainable against the potential impact of explosion.

However, the sensitivity analysis showed that the ignition point and fuel composion significantly influence the degree of explosion impact on the structures, which implies that controlling of ignition points and fuel-air ratio can be a good safety means to mitigate the impact of explosion.

Lastly, it may be right to point out that the present paper set out to show the gaps in the current regulatory provisions, especially with regard to addressing the neccessity of higher safety level for high-pressure FPRs. It is believed this study has achieved this, or at least made a start on it. Theferefore, it is expected that this work will be of some interest to the rule- and standard-makers who may well believe that developing more explicit and quantified guidelines is an urgent task.

\section{Acknowledgement}

The authors would like to express their gratitude to Mr. Sayyoon Park (University of Strathclyde), Korean Register of Shipping (especially, Mr. Seungman Ha) and Korean Ministry of Oceans and Fisheries for their valuable support, comments and suggestions. They have contributed considerably to this study. Last but not least, we appreciate all IMO member states who circulated and discussed this paper from the viewpoint of enhancing current IGF Code. 


\section{References}

ABS, 2014. Bunkering of Liquefied Natural Gas-fueled Marine Vessels in North America. ABS, Houston Texas USA.

ABS, 2015, Guide for Propulsion And Auxiliary Systems For Gas Fuelled Ships, ABS, Houston Texas UAS.

ADN Administrative Committee, 2014. Proposed text of a derogation regarding the use of LNG, Geneva Swithland.

Aymelek, M. et al., 2015. Challenges and opportunities for LNG as a ship fuel source and an application to bunkering network optimisation, London UK, Taylor \& Francis Group.

CCPS, 1989. Guidelines for Process Equipment Reliability Data with Data Tables. CCPS, New York, USA.

CD-adapco, 2014. User Guide: STAR-CCM+ Version 9.02.

Crowl, D.A., J. F. Louvar, 1990. Chemical Process Safety: Fundamentals with Applications. Prentice Hall, New Jersey USA.

Dan, S. et al, 2014. Quantitative risk analysis of fire and explosion on the top-side LNGliquefaction process of LNG-FPSO. Process Safety and Environmental Protection 92, 430441.

DNV, 2012. failure frequency guidance: Process Equipment Leak Frequency Data for use in QRA, Oslo Norway.

DNV, 2013. Report for Skangass AS, Appendix A - Assumptions Register, Reg. No.: 2013-4091 / 17TLT29-4, DNV.

DNV GL, 2014. Recommended Practice - Development and operation of liquefied natural gas bunkering facilities. DNV GL, Oslo Norway.

DNV, 2015. DNV Rules for Classification of Ships, Part 3 Chapter 1 Hull structural design - Ships with length 100 metres and above.

EPRI, 1995. Advanced Light Water Reactor Utility Requirements Document (Volume III). EPRI, California, USA.

Gavelli, F., et al., 2011. Evaluating the potential for overpressures from the ignition of an LNG vapor cloud during offloading. Journal of Loss Prevention in the process industries 24 (6), 908-915.

Germany and Norway, 2012. HAZID report, IMO BLG, London.

IMO, 2002. MSC/Circ.1023, MEPC/Circ.392: Guidelines for Formal Safety Assessment (FSA) for Use in the IMO Rule-making Process, in: IMO (Ed.), London, UK.

IMO, 2017. International Code of Safety for Ships using Gases or other Low-flashpoint Fuels (IGF Code) IMO, London, UK.

ISO, 2013. 16903: Characteristics of LNG influencing design and material selection, Geneva Switzerland.

ISO, 2015. Guidelines for systems and installations for supply of LNG as fuel to ships. ISO, Geneva Switzerland.

John L. and R. Pitblado, 2010. LNG RISK BASED SAFETY Modeling and Consequence Analysis. A John Wiley \& Sons, INC, New Jersey USA. 
Kim, H., et al., 2005. Risk assessment of membrane type LNG storage tanks in Koreabased on fault tree analysis. Korean Journal of Chemical Engineering 22 (1), 1-8.

Kletz, T., 1991. An engineer's view of human error. IChemE, Rugby UK.

Korean Register, 2015. LNG Fuelled Ready Ship For VLOC, Busan, South Korea.

Lee, S., et al., 2015. Fire risk comparison of fuel gas supply systems for LNG fuelled ships. Journal of Natural Gas Science and Engineering 27, 1788-1795.

Lloyd's Register, 2012. LNG-fuelled deep sea shipping: The outlook for LNG bunker and LNG-fuelled newbuild demand up to 2025. Lloyd's Register, London UK.

NORSOK, 2001. Standard Z-013 - Risk and emergency preparedness analysis. NORSOK, Norway.

MAN Diesel and Turbo, ME-GI Dual Fuel MAN B\&W Engines: A Technical, Operational and Cost-effective Solution for Ships Fuelled by Gas, Copenhagen, Denmark.

MAN Diesel and Turbo, 2013, Flexible Dual Future: MAN B\&W ME-GI Engine [online video], http://www.youtube.com/watch?v=V0MVdIQYonM, (accessed 8 April 2015)

OGP, 2010. Risk Assessment Data Directory, Ignition probabilities, London, UK.

OREDA, 2009. Offshore Reliability Data Volume 1 Topside Equipment, 5th edn. OREDA, Trondheim, Norway.

Ramiro, J.M.S., P. A. B. Aisa, 1998. Risk Analysis and Reduction in the Chemical Process Industry. Blackie Academic \& Professional, London, UK.

Republic of Korea, 2014. Leakage analysis and gas explosion simulation in the LNGfuelled ships. IMO, London, UK.

Piellisch, R., 2013. 'Container Ship LNG? Plenty of Time', HHP Insight, , [website] http://hhpinsight.com/marine/2013/01/container-ship-lng-plenty-of-time/ (accessed $18 \mathrm{Jan}$ 2016).

Versteeg, H. and W. Malalasekera, 2007. An Introduction to Computational Fluid Dynamics. Pearson Education, Essex UK. 


\section{Appendix I}

To identify the minimum leak rate which can lead to LEL of fuel-air mixture, a simple ventilation analysis was conducted by using STAR-CCM+. Under effective ventilation condition with capacity of $2.57 \mathrm{~kg} / \mathrm{s}$ equivalent to 30 times air change each hour for the FPR $(17 \mathrm{~m} \times 6 \mathrm{~m} \times 2.5 \mathrm{~m})$, it was found that the continuous leak with $0.07 \mathrm{~kg} / \mathrm{s}$ converged to the volume fraction of $\mathrm{CH}_{4}$ of 5\% (same as methane LEL) as shown in Figs A_1 and A_2. Therefore, the probability of explosion for small leak rate of less than $0.07 \mathrm{~kg} / \mathrm{s}$ was ignored.

In order to verify the mesh independence in the explosion analysis, a mesh convergence test was conducted with three different base mesh sets $(0.02 \mathrm{~m}, 0.015 \mathrm{~m}$ and $0.01 \mathrm{~m})$. Fig. A_ 3 shows the result. It can be seen that the finer two mesh systems produce more or less identical results with deviations well within the acceptable level. 


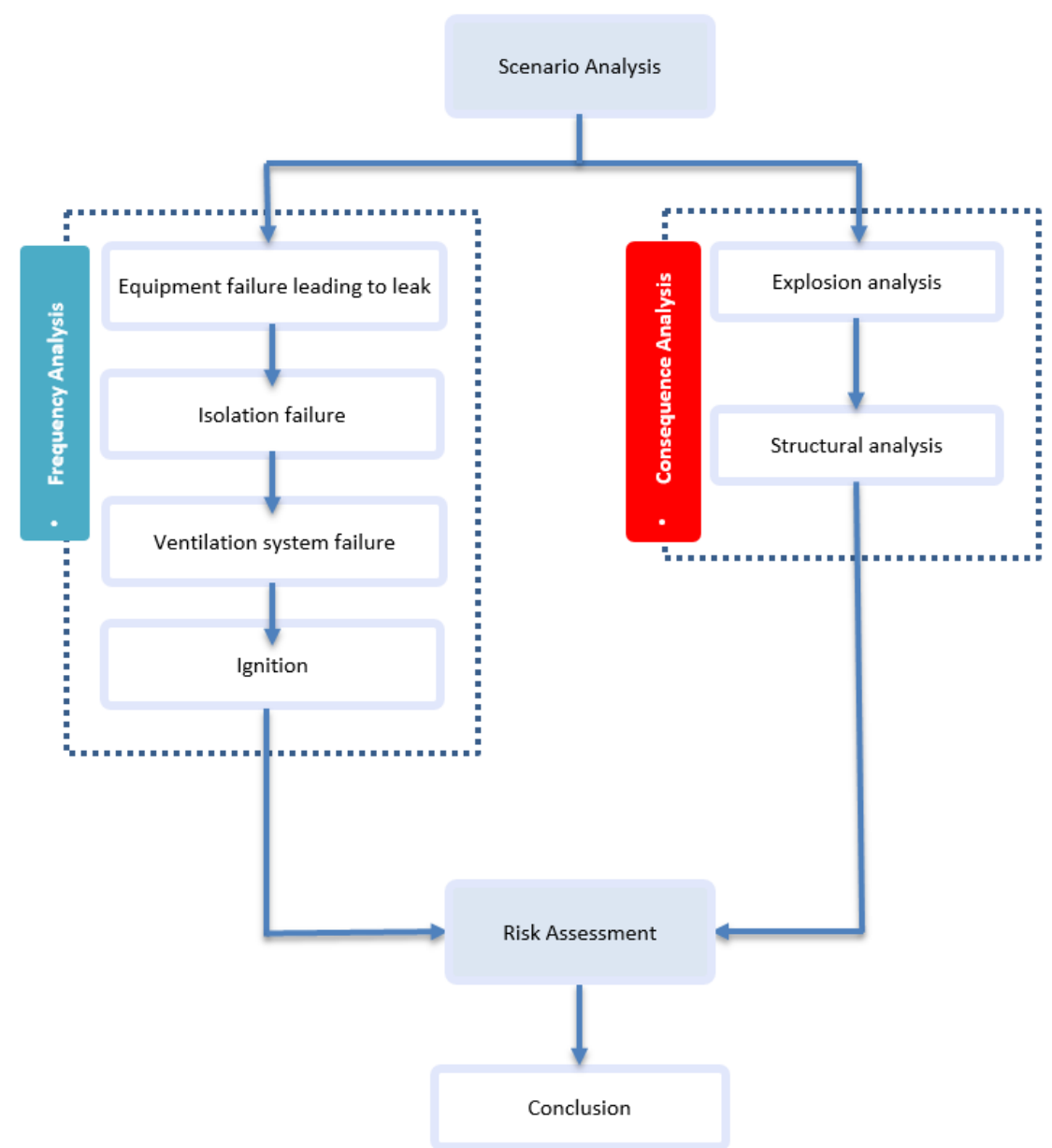

Fig. 1 Proposed risk assessment procedure for FPR. 


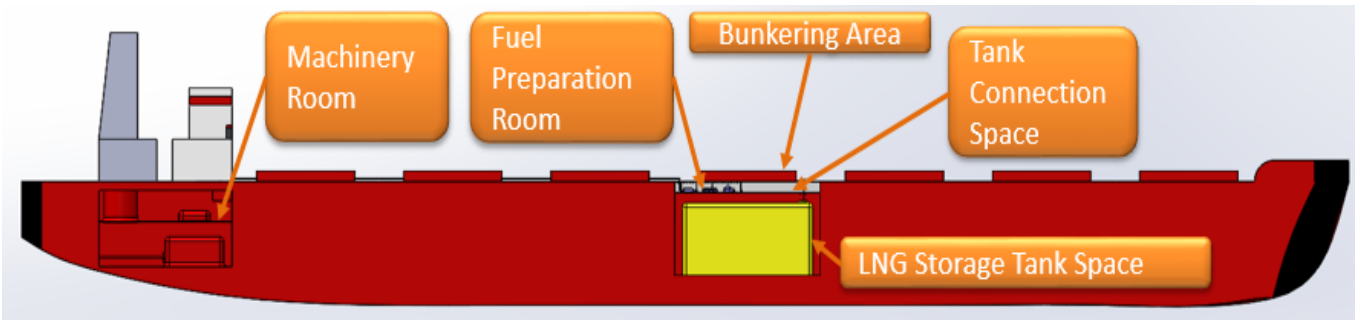

Fig. 2 A proposed general arrangement of the LNG fuel system. 


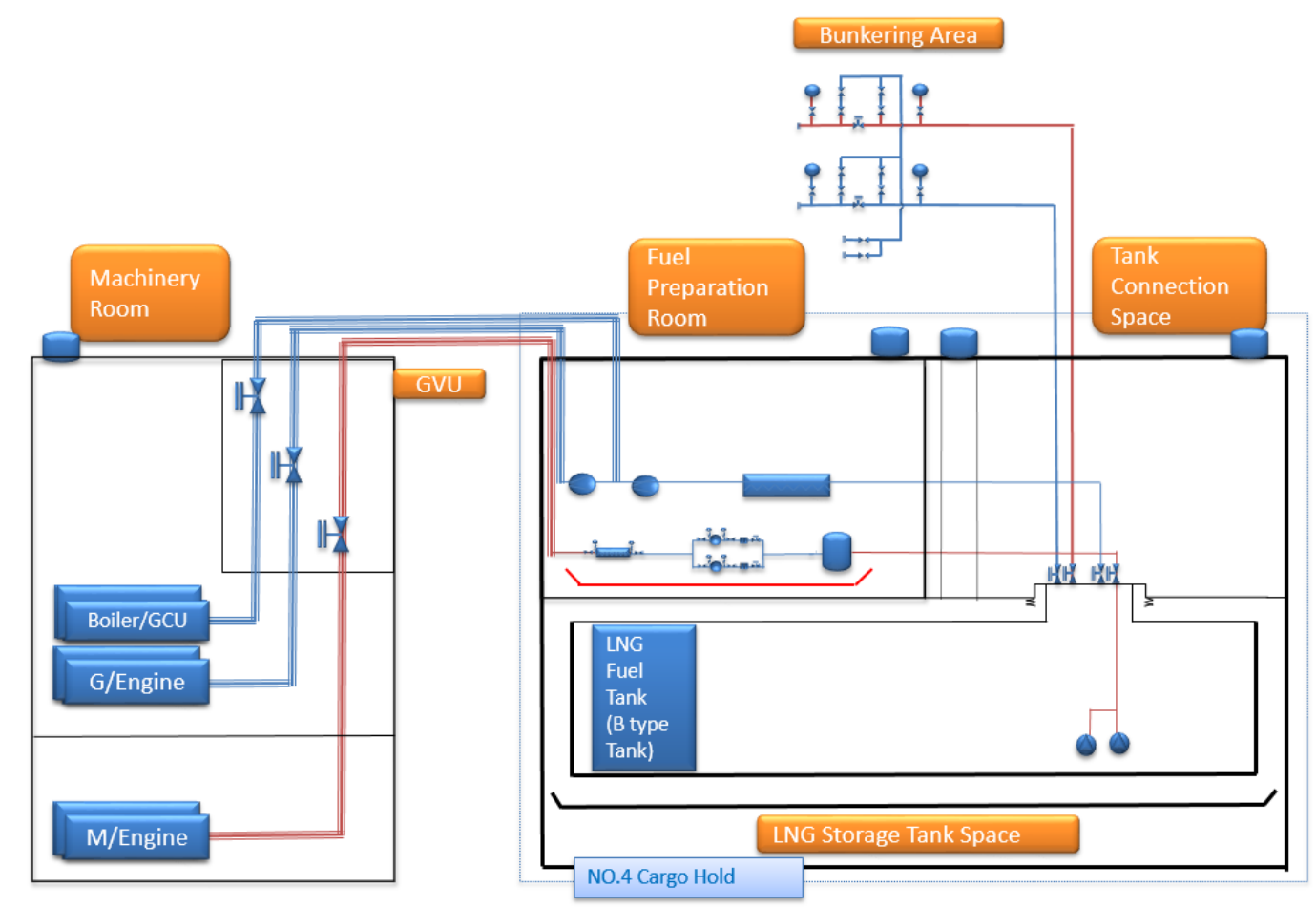

Fig. 3 Concept piping diagram of the fuel system. 


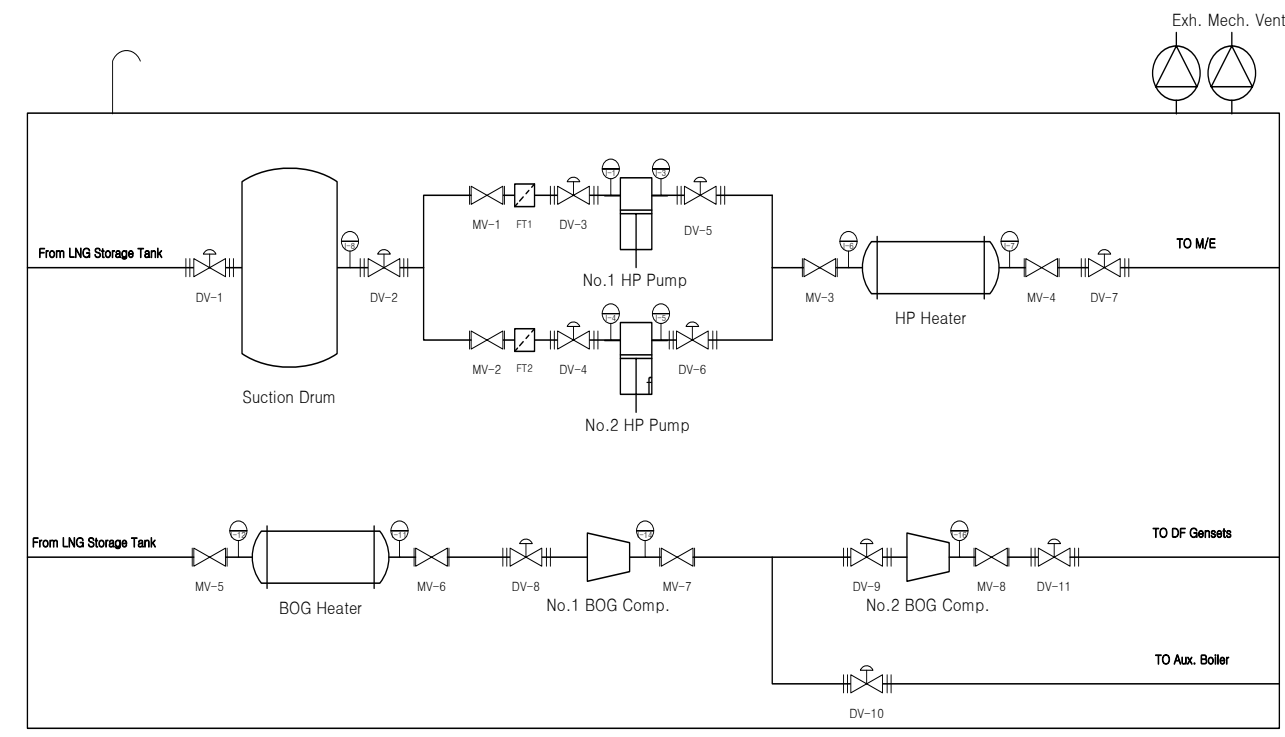

Fig. 4 Concept design of the FGSS for the case ship. 


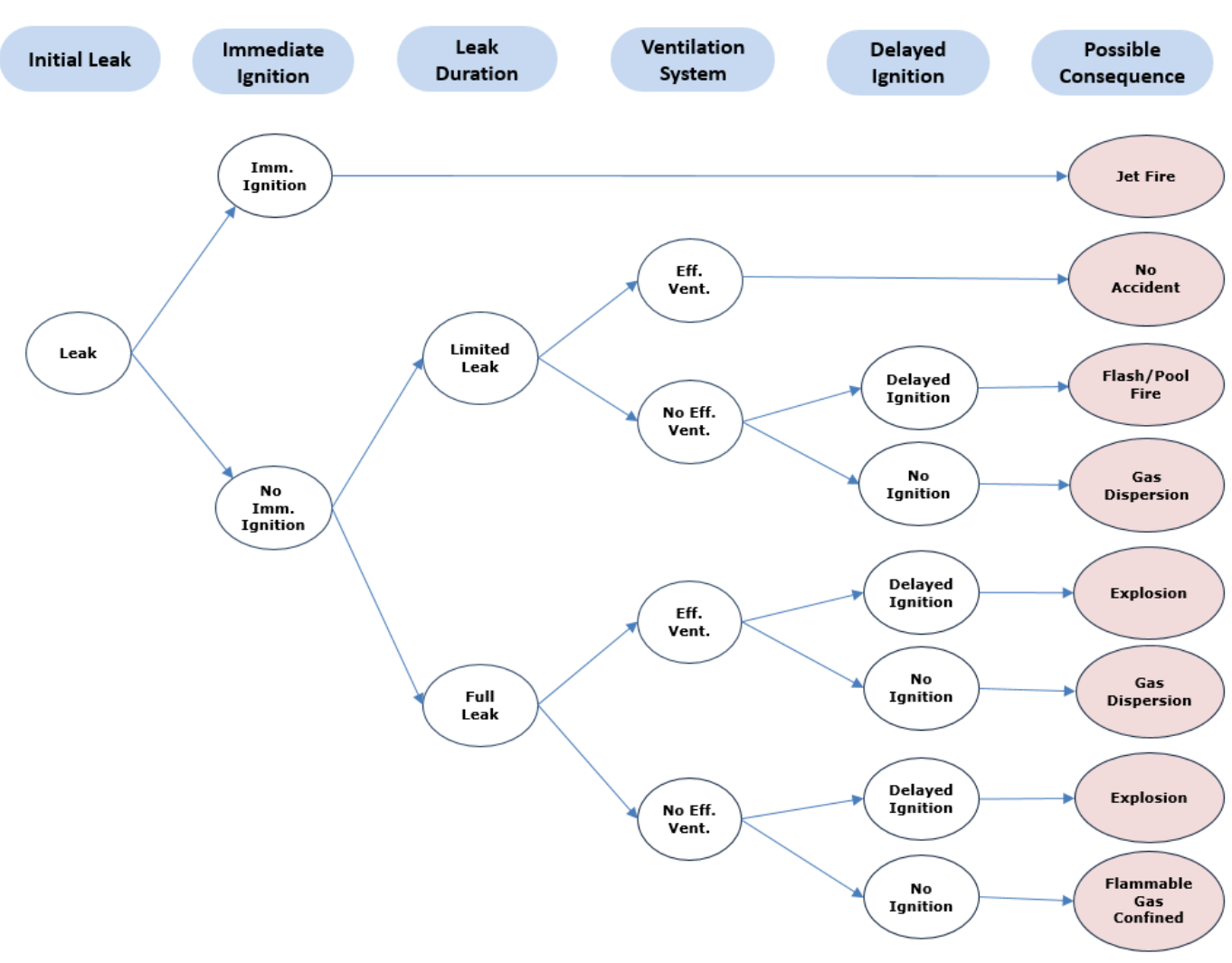

Fig. 5 The event tree. 


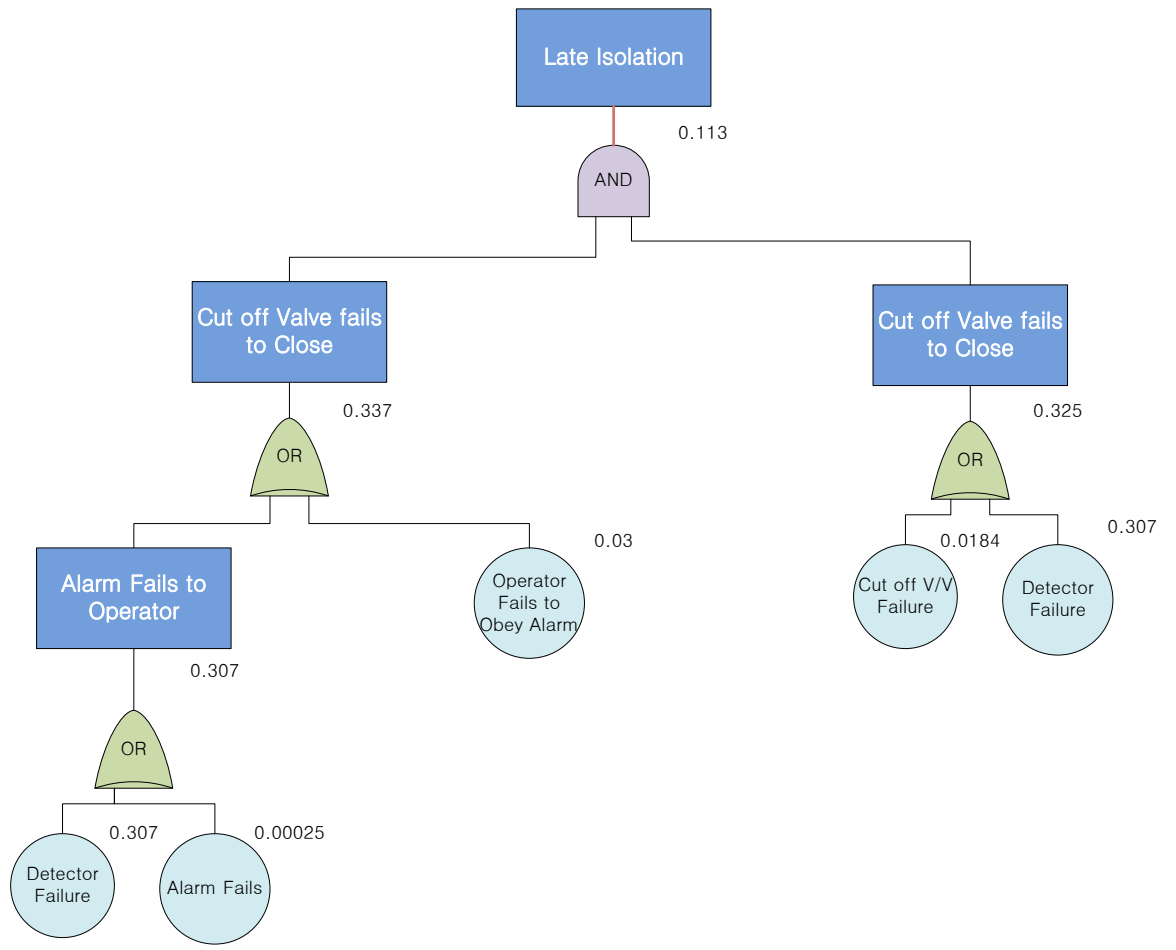

Fig. 6 FTA for delayed isolation. 


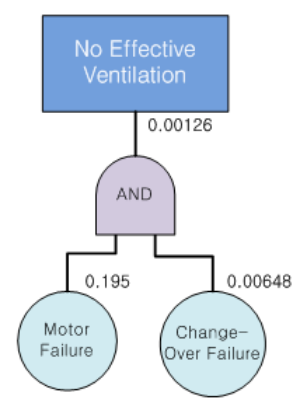

Fig. 7 FTA for ventilation failure. 


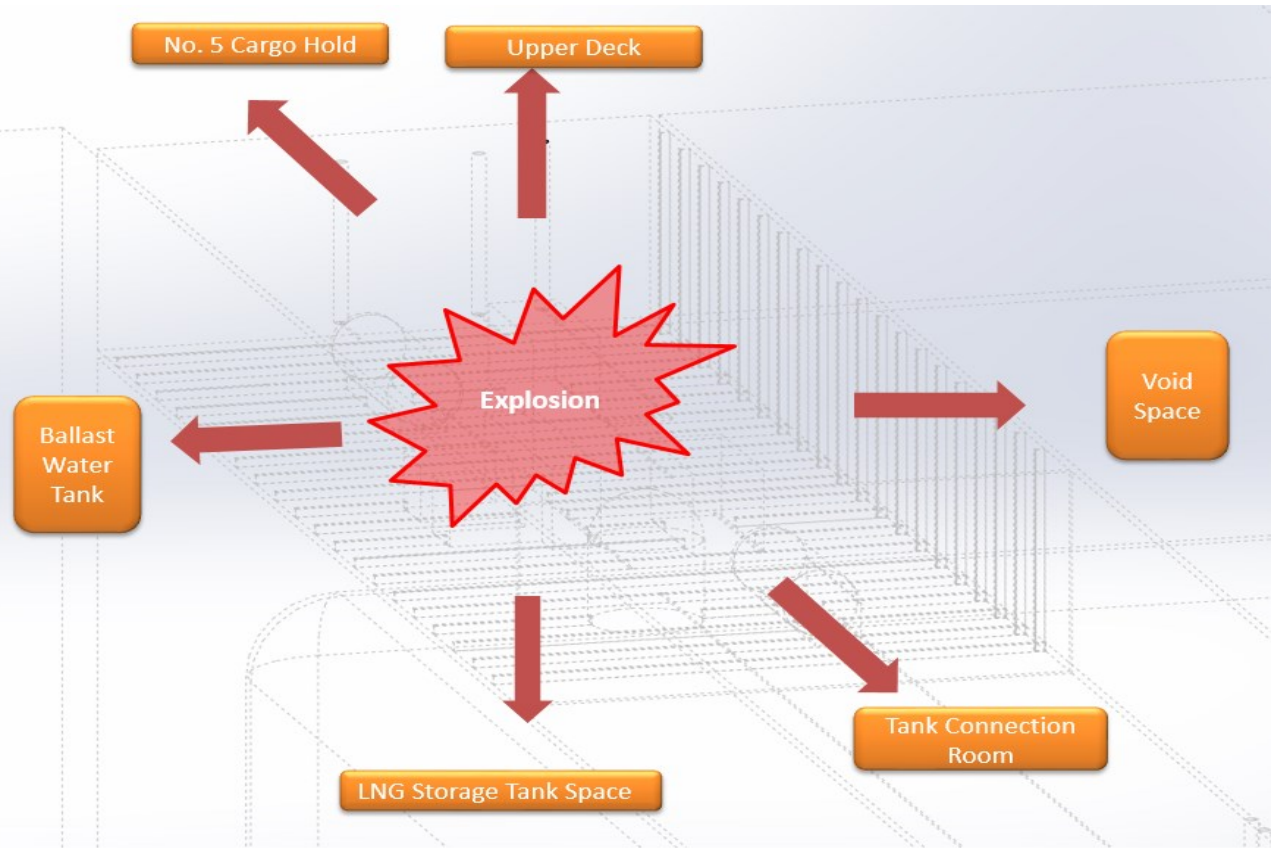

Fig. 8 Possible directions of explosion impact. 


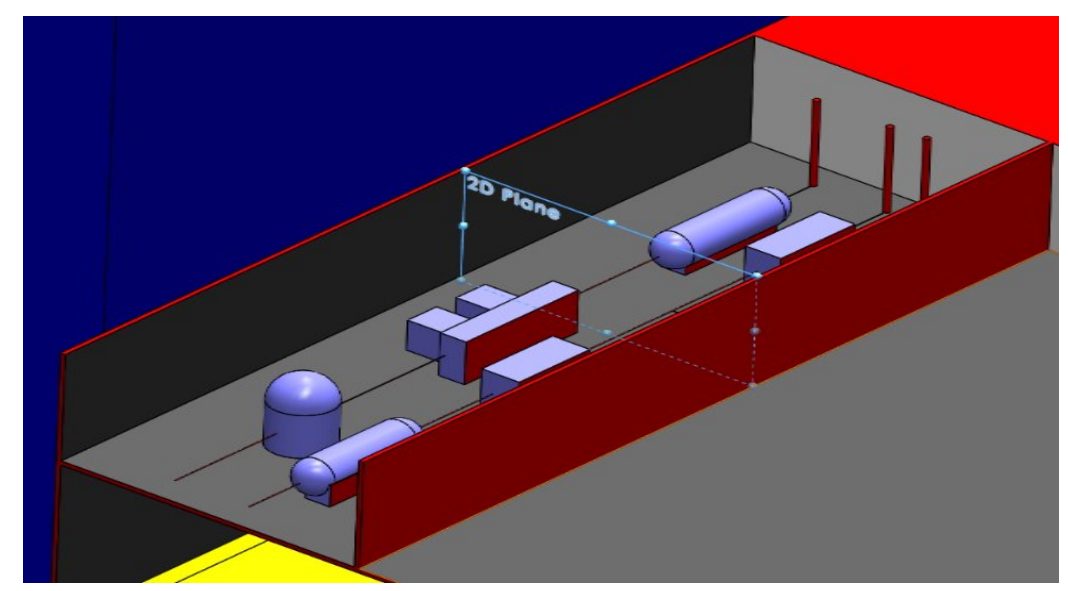

Fig. 9 A 3D model of the FPR 


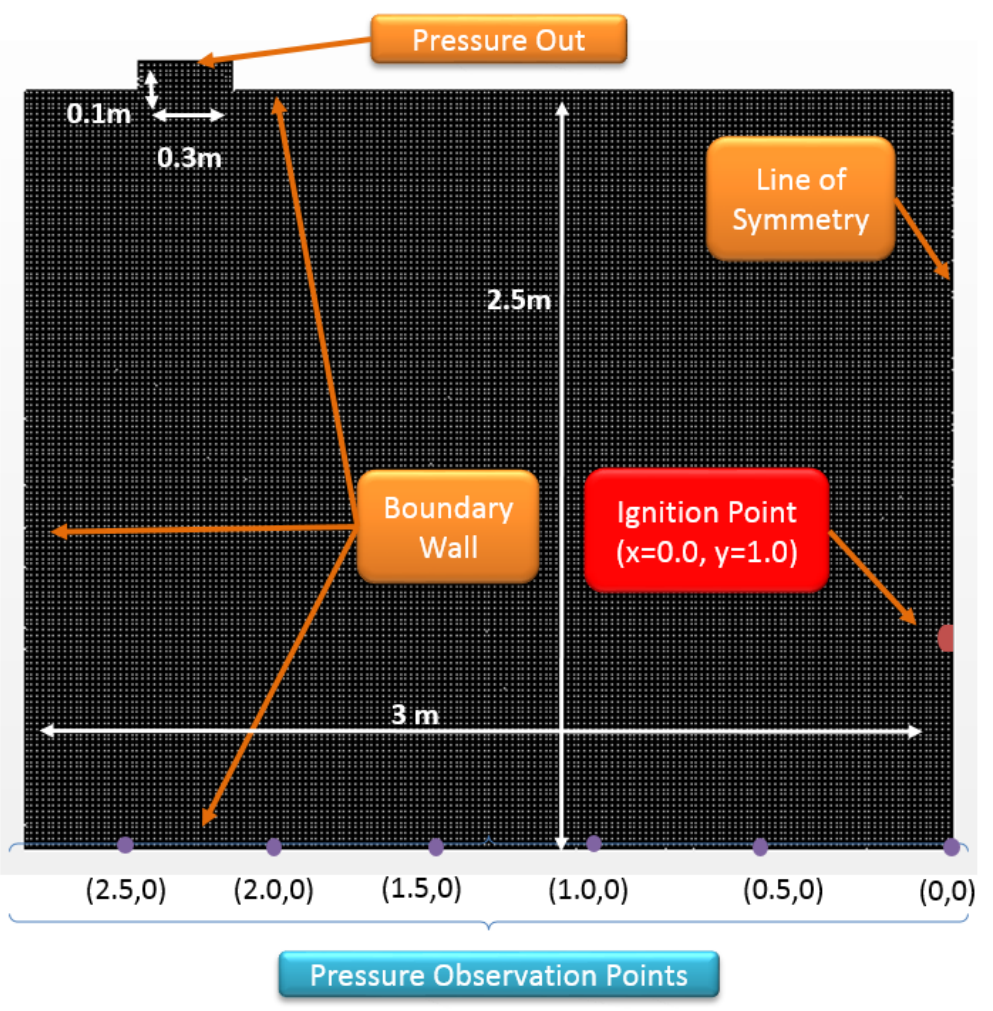

Fig. 10 A 2D Model of the FPR. 


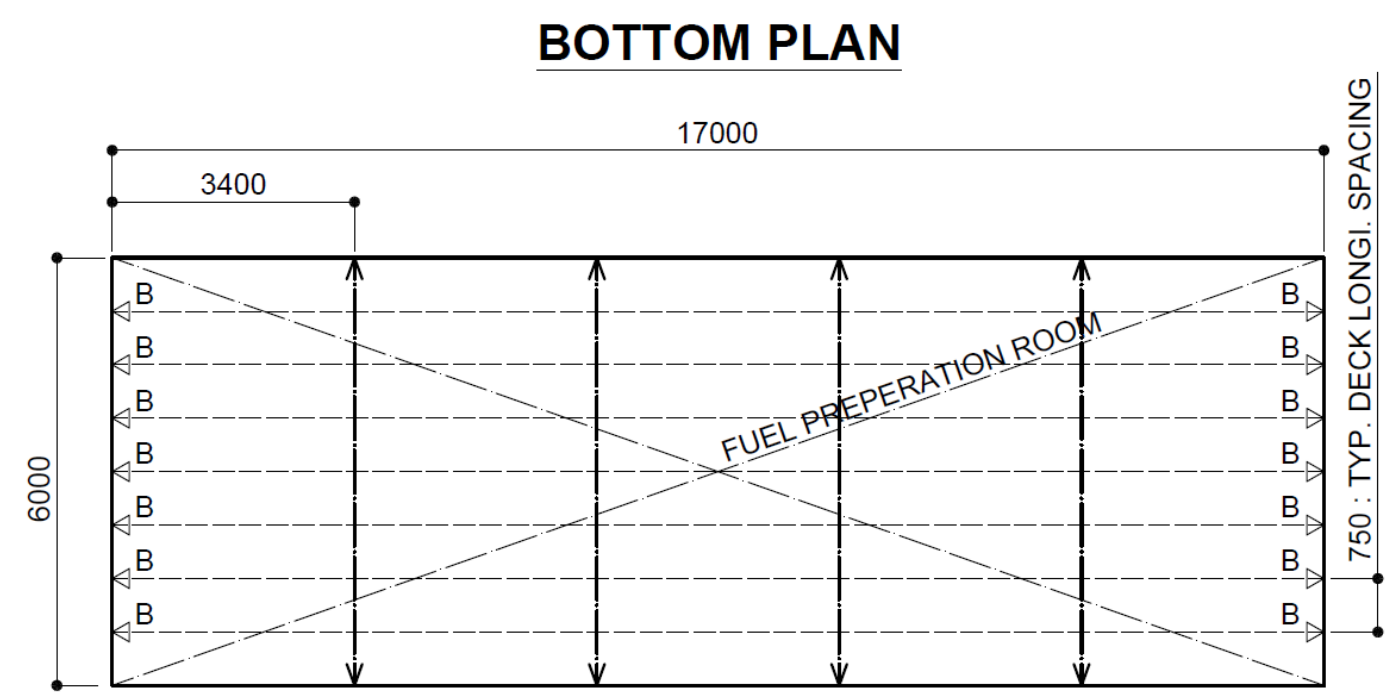

Fig. 11 Details of the FPR floor structure. 


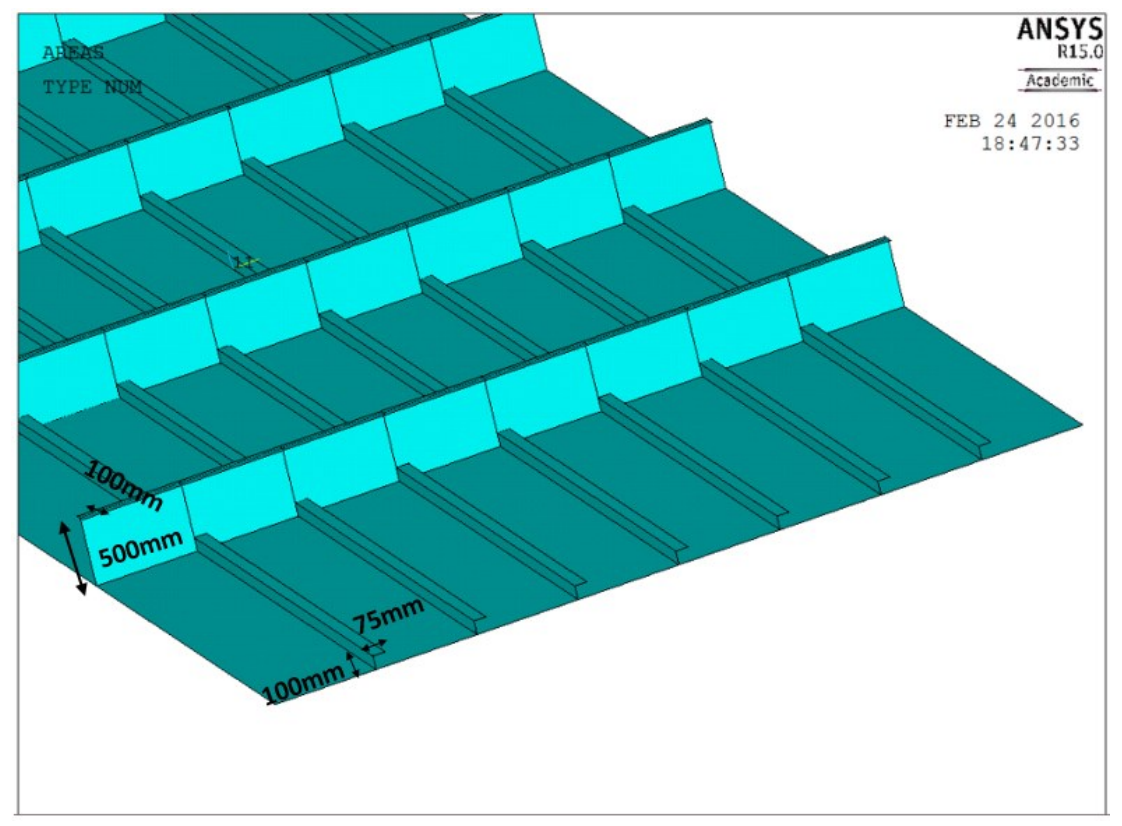

Fig. 12 The stiffened bottom panel of the FPR for Case 1. 


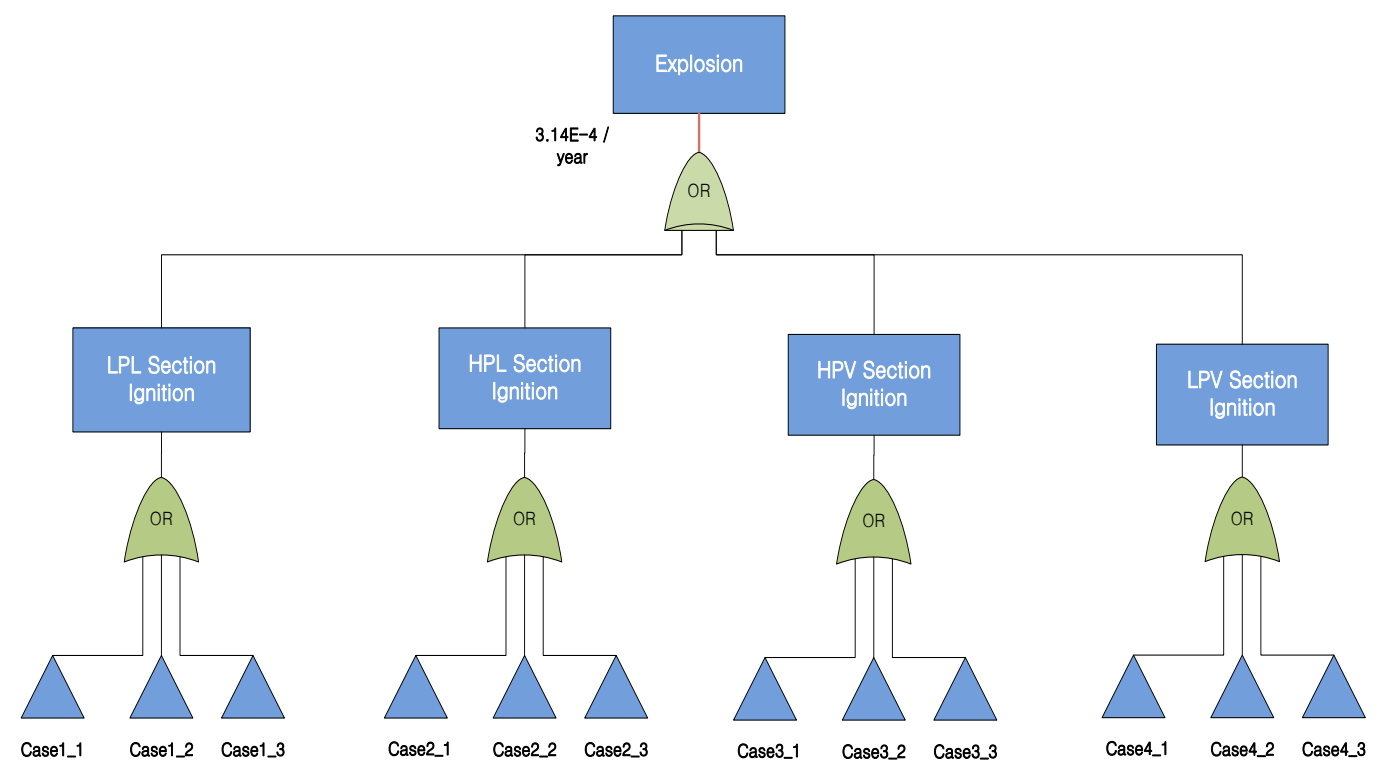

Fig. 13 FTA showing the overall frequency of explosion. 


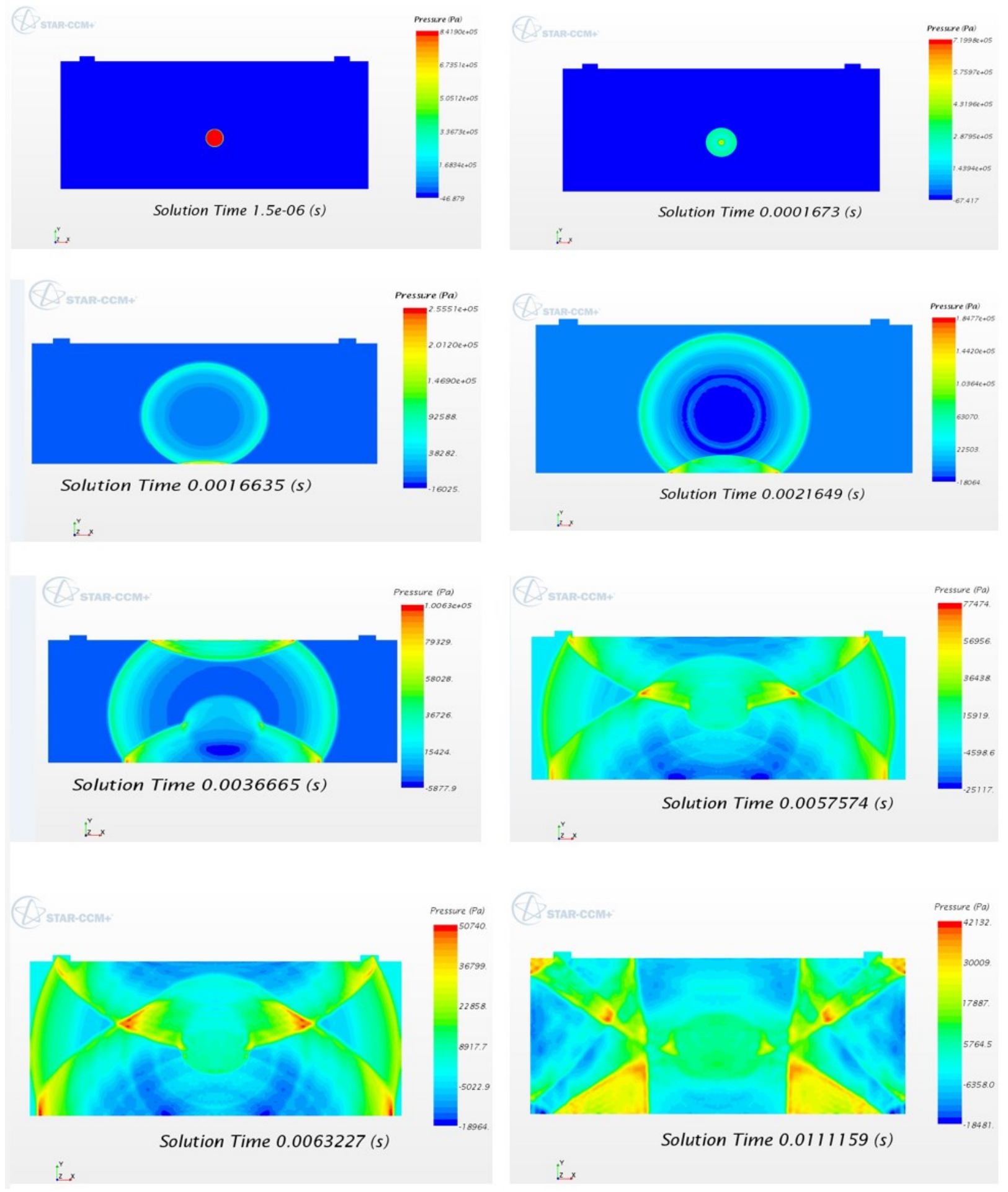

Fig. 14 Progress of explosion. 


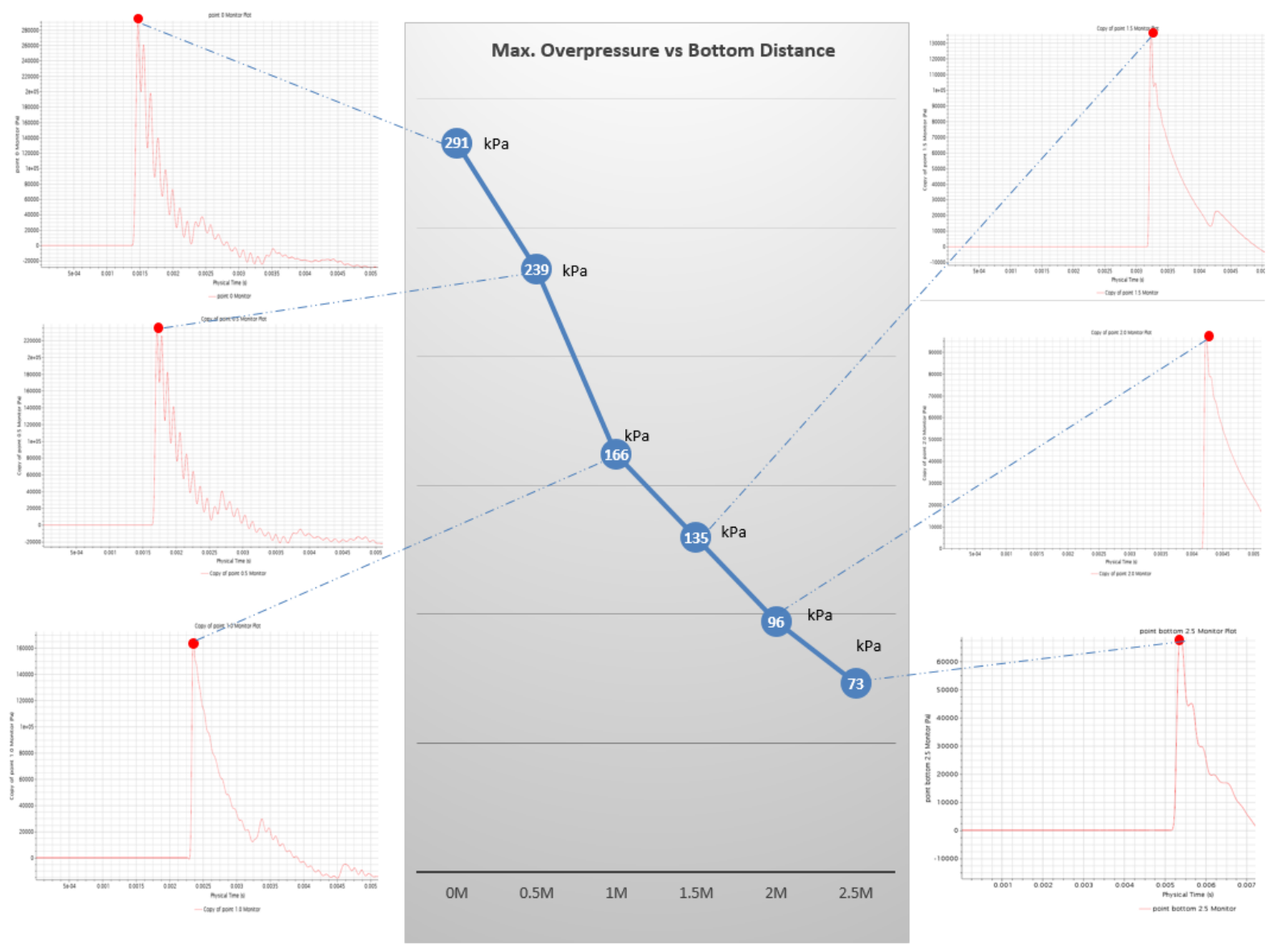

Fig. 15 Maximum pressure on the floor at various distances from the ignition point. 


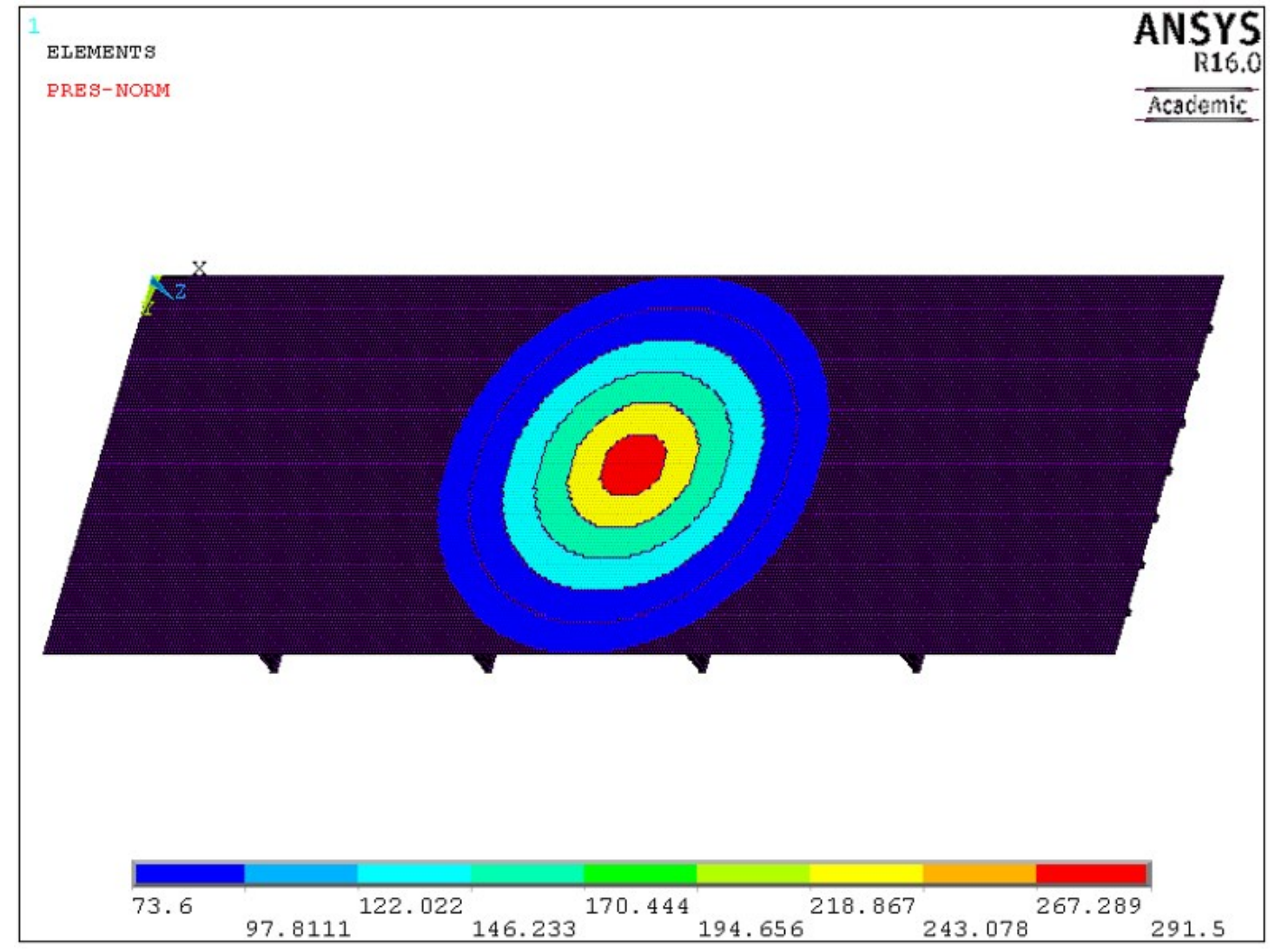

Fig. 16 Pressure load applied in FE analysis. 

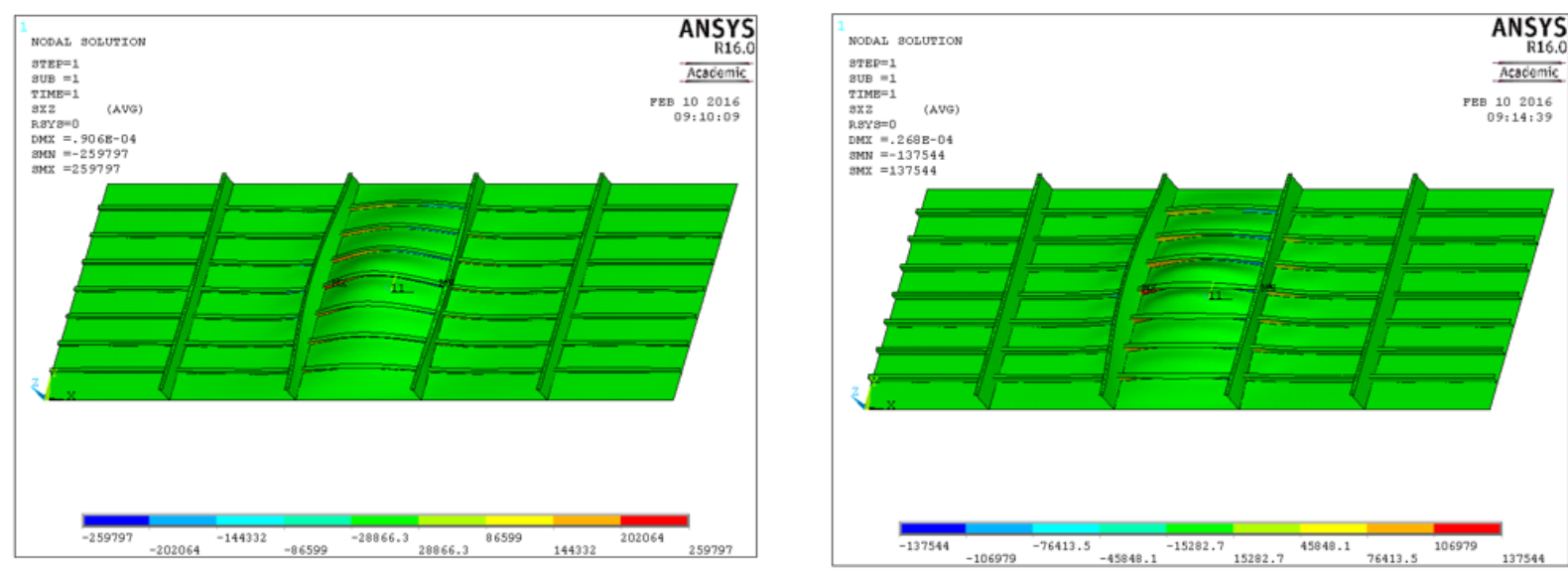

c)
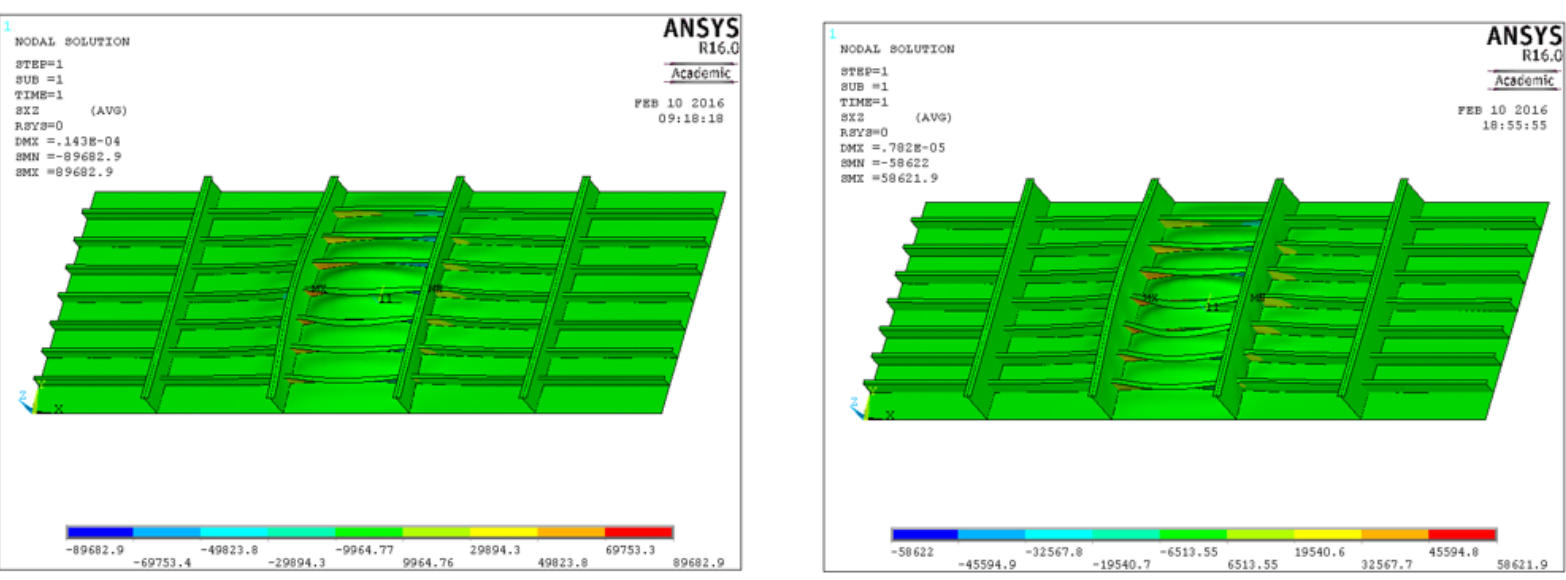

Fig. 17 Shear stress on the floor: (a) Case 1; (b) Case 2; (c) Case 3; (d) Case 4. 

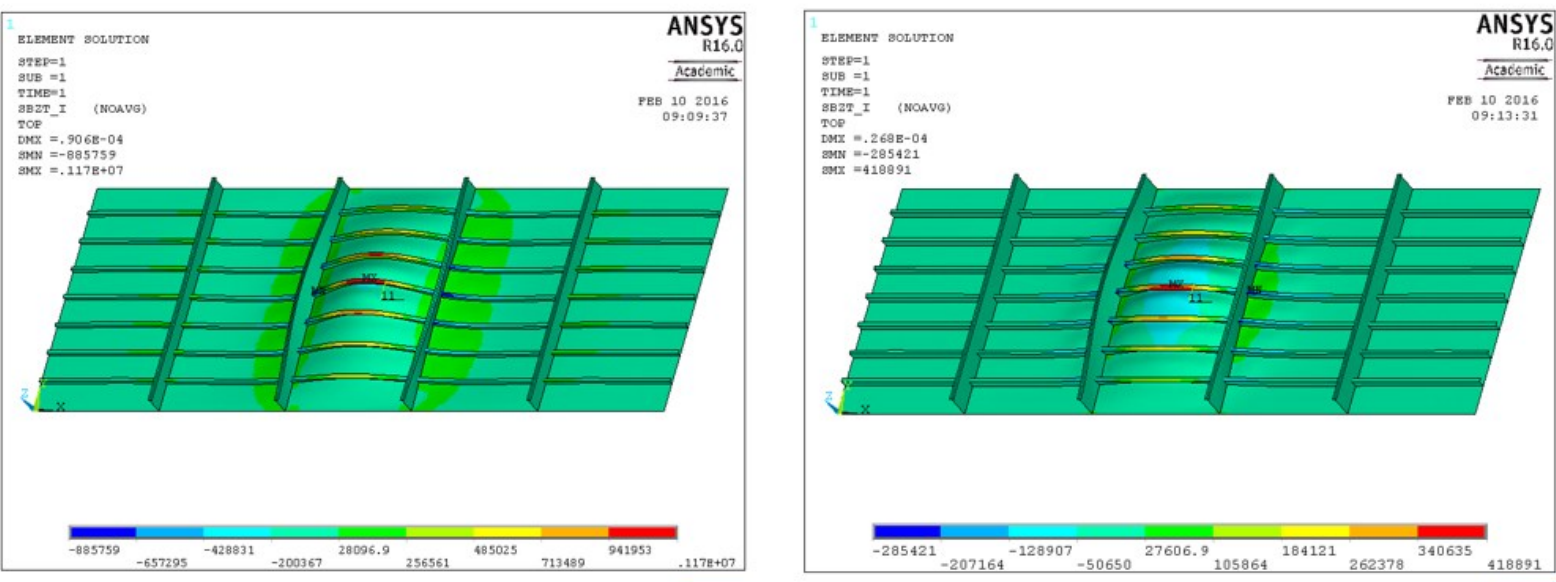

c)

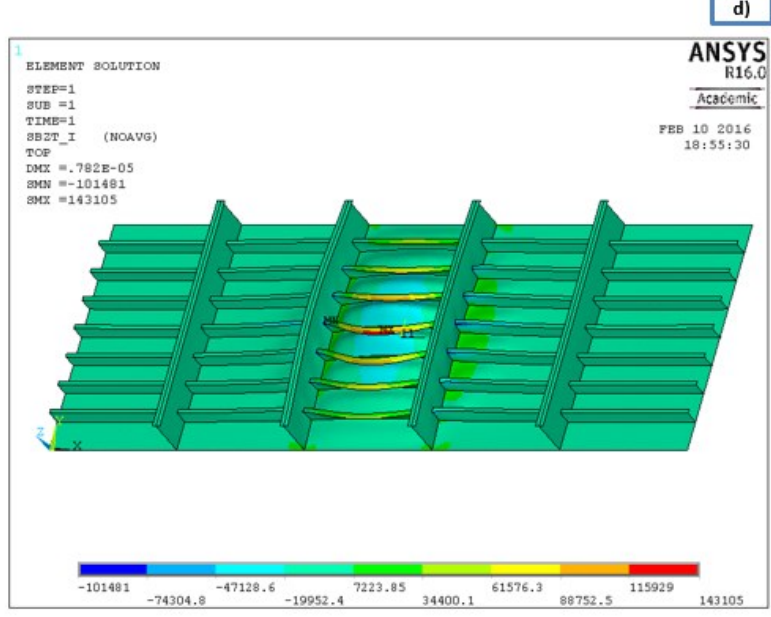

Fig. 18 Bending stress on the floor: (a) Case 1; (b) Case 2; (c) Case 3; (d) Case 4. 

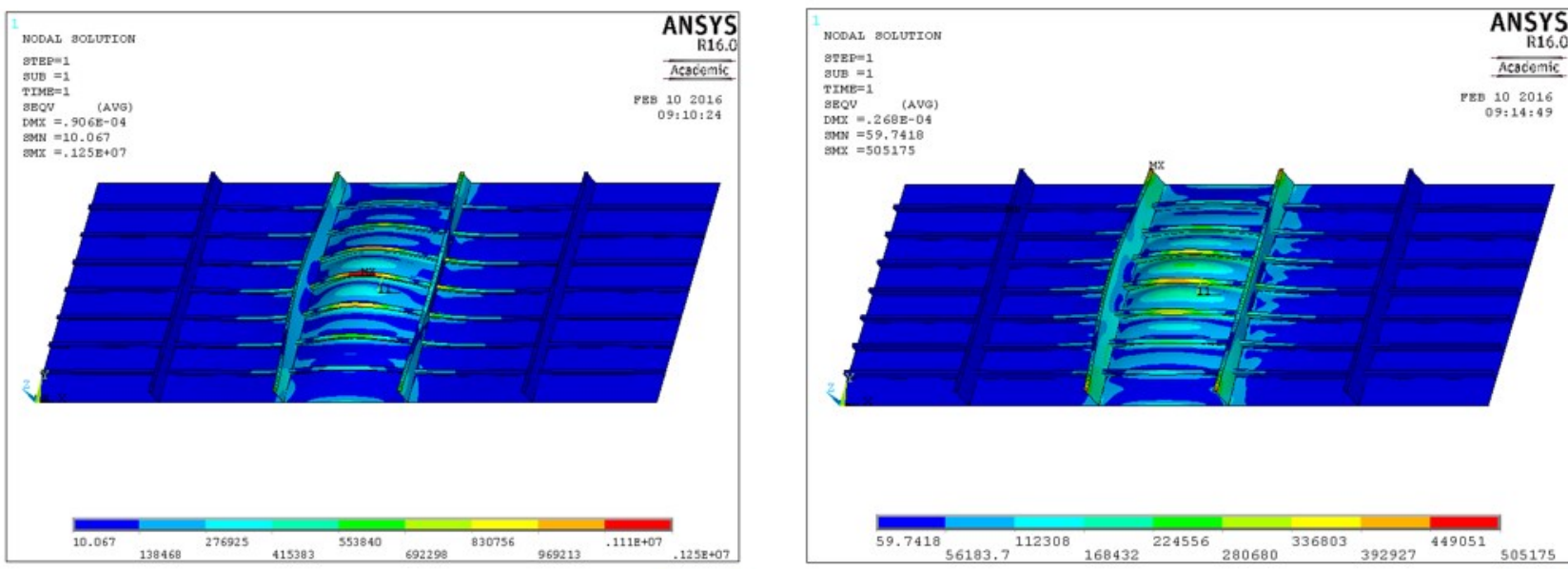

c)

d)
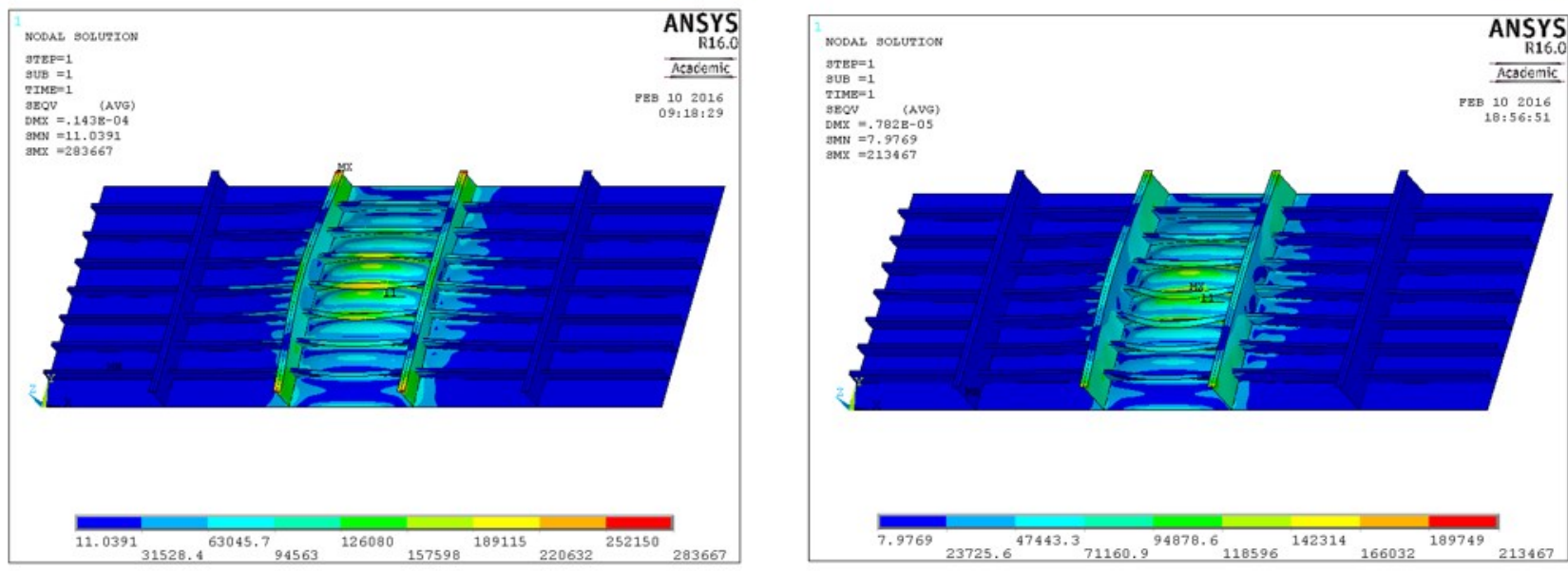

Fig. 19 Equivalent stress on the floor: (a) Case 1; (b) Case 2; (c) Case 3; (d) Case 4. 

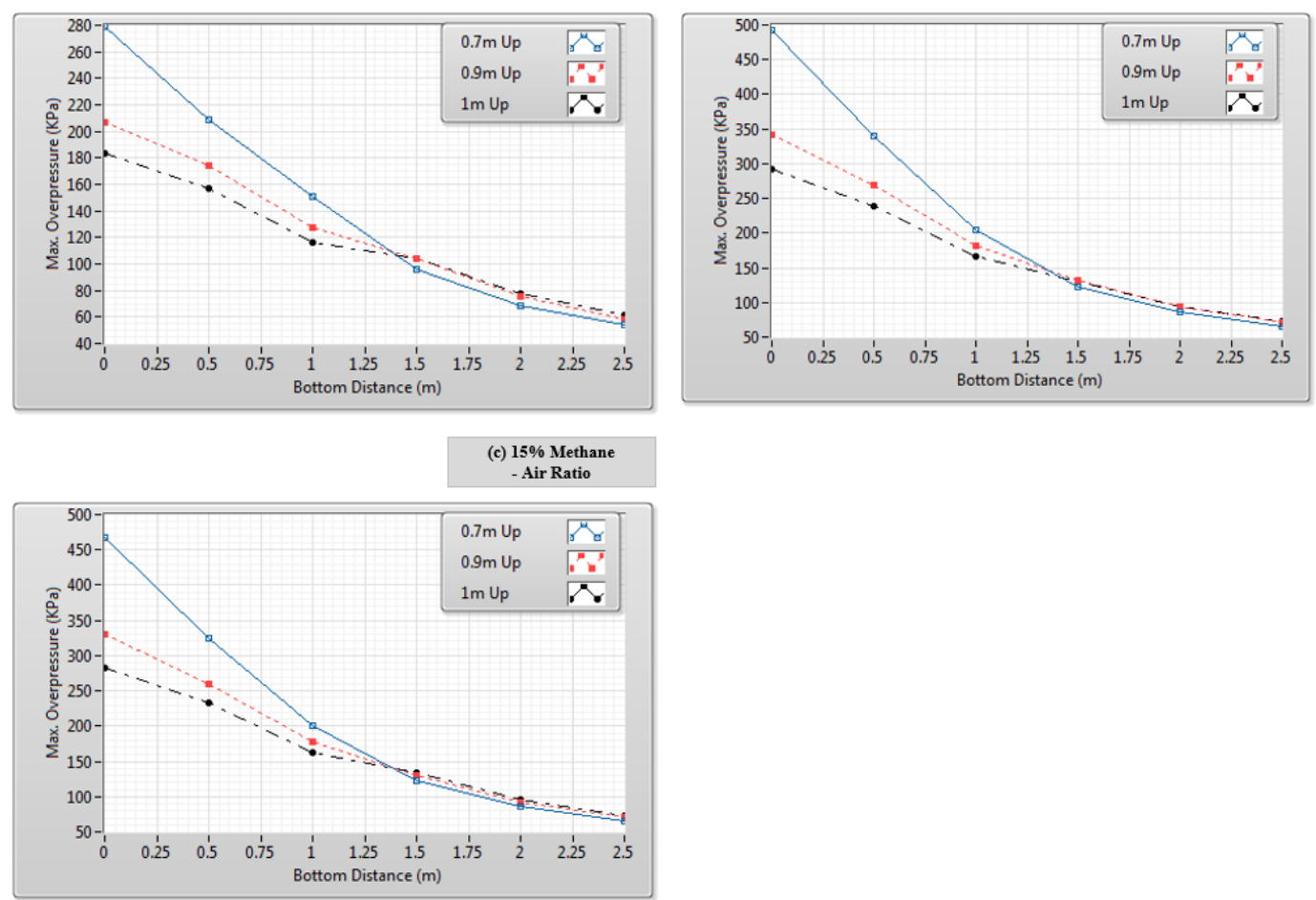

Fig. 20 Maximum pressure on the floor at various distances from the ignition points and methane compositions. 


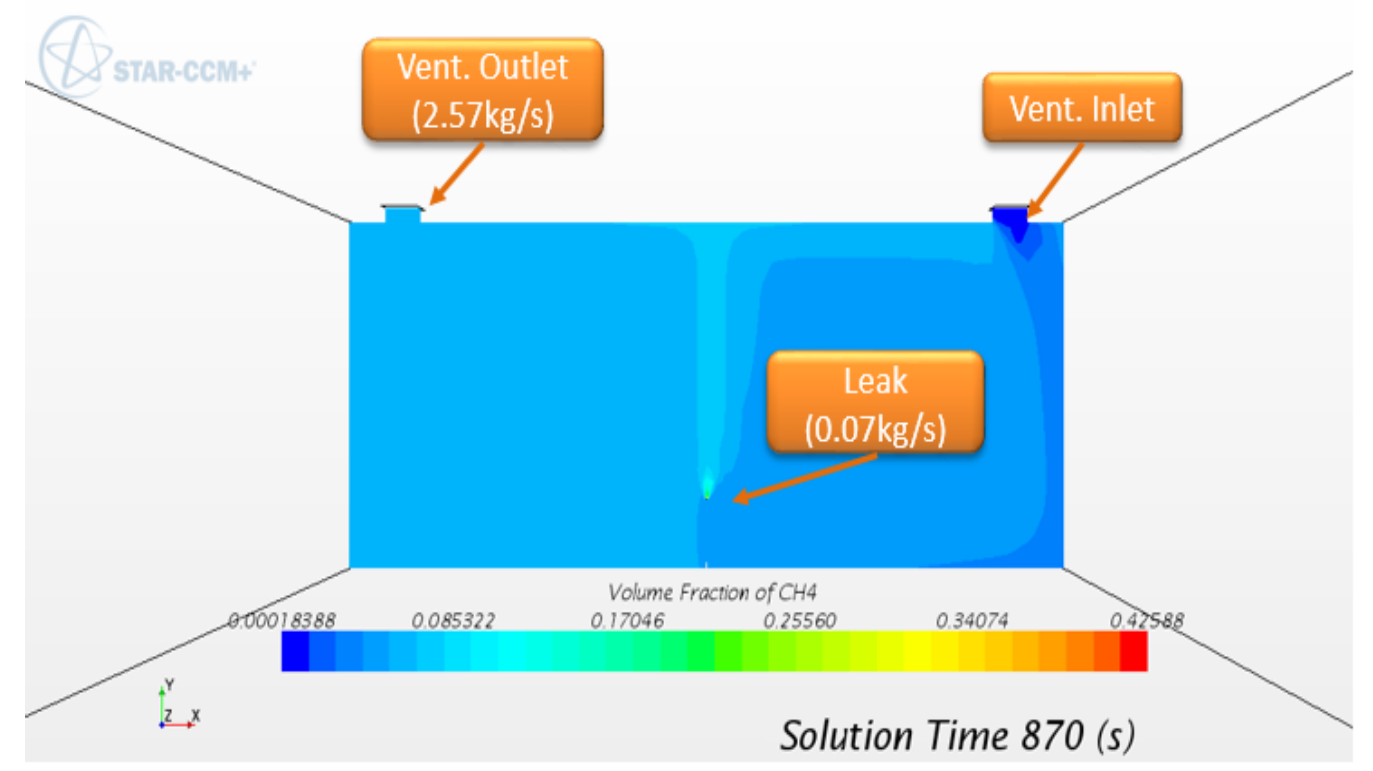

Fig. A_1 Ventilation analysis of FPR at $0.07 \mathrm{~kg} / \mathrm{s}$ leak. 


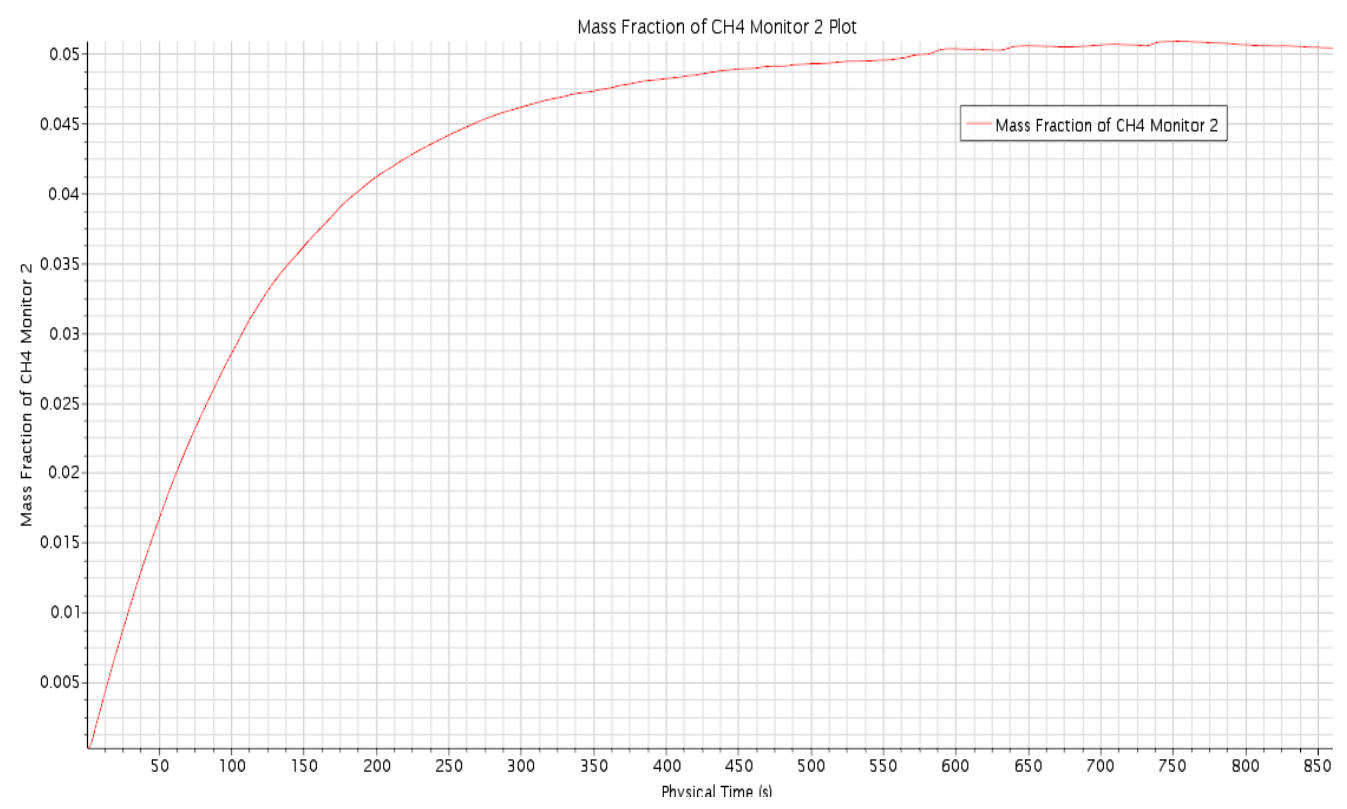

Fig. A_2 Mass fraction of $\mathrm{CH}_{4}$ over time at $0.07 \mathrm{~kg} / \mathrm{s}$ leak. 


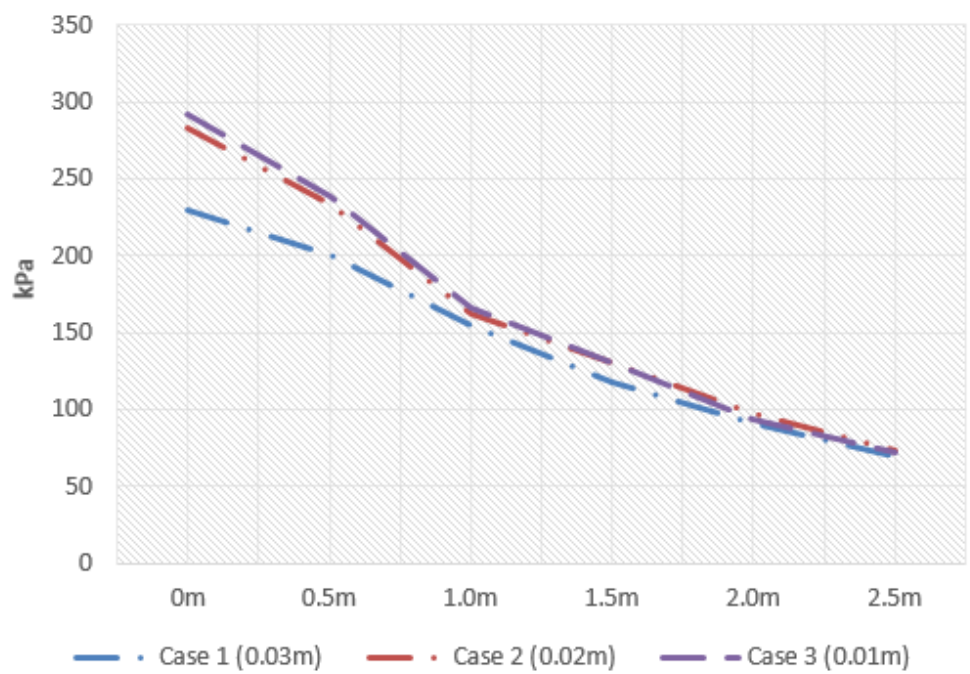

Fig. A_3 Mesh convergence test. 
Table 1 General specifications of the case ship (Korean Register, 2015).

\begin{tabular}{cc}
\hline Items & Specifications \\
\hline L x B x D & $328.0 \mathrm{~m} \times 55.0 \mathrm{~m} \times 29.0 \mathrm{~m}$ \\
Main Engine & Hyundai MAN B\&W 6G80ME-C9 (before retrofit) \\
MCR/NCR & $20,680 \mathrm{~kW} \times 65.8 \mathrm{rpm} / 17,578 \mathrm{~kW} \times 62.3 \mathrm{rpm}$ \\
Speed & $14.6 \mathrm{knots}$ at sea trial \\
F.O. Consumption & abt. 67 tons/day \\
Cruising range & abt. 25,000 miles per one voyage from Brazil to East Asia \\
Cruising day & 300 days per year at NCR \\
\hline
\end{tabular}


Table 2 Specifications of the FGSS.

\begin{tabular}{cc} 
Items & Specifications \\
Mass flow rate for M/E & $2,727.69 \mathrm{~kg} / \mathrm{h}$ \\
Diameter of fuel supply line & $12.5 \mathrm{~mm}$ \\
Working pressure & LPL for 5 bar, HPL for 300 bar \\
Working temperature & Liquid for $112 \mathrm{~K}$, Gas for $318 \mathrm{~K}$ \\
\hline
\end{tabular}


Table 3 Frequency of initial leak with respect to leak size.

\begin{tabular}{|c|c|c|c|c|c|}
\hline \multirow{2}{*}{ Section } & \multirow{2}{*}{ Equipment List } & \multirow{2}{*}{$\begin{array}{c}\text { No. of } \\
\text { Equipment }\end{array}$} & \multicolumn{3}{|c|}{ Frequency of Leak (/year) } \\
\hline & & & 3mm leak & $10 \mathrm{~mm}$ leak & Full leak \\
\hline \multirow{8}{*}{$\mathbf{L P L}$} & Actuated valves & 4 & $2.19 \mathrm{E}-03$ & $6.89 \mathrm{E}-04$ & $3.12 \mathrm{E}-04$ \\
\hline & Filters & 2 & $3.71 \mathrm{E}-03$ & $1.83 \mathrm{E}-03$ & $1.50 \mathrm{E}-03$ \\
\hline & Flange & 12 & $4.38 \mathrm{E}-04$ & $1.59 \mathrm{E}-04$ & $1.52 \mathrm{E}-04$ \\
\hline & Manual valves & 2 & $1.06 \mathrm{E}-04$ & $4.60 \mathrm{E}-05$ & $3.04 \mathrm{E}-05$ \\
\hline & Pipe & 14 & $1.33 \mathrm{E}-02$ & $4.69 \mathrm{E}-03$ & $2.17 \mathrm{E}-03$ \\
\hline & Suction drum & 1 & $9.46 \mathrm{E}-04$ & $5.49 \mathrm{E}-04$ & $8.57 \mathrm{E}-04$ \\
\hline & $\begin{array}{c}\text { Small gauge } \\
\text { fittings }\end{array}$ & 3 & $9.32 \mathrm{E}-04$ & $4.08 \mathrm{E}-04$ & $2.59 \mathrm{E}-04$ \\
\hline & \multicolumn{2}{|c|}{ Total } & $2.16 \mathrm{E}-02$ & $8.37 \mathrm{E}-03$ & $5.28 \mathrm{E}-03$ \\
\hline \multirow{6}{*}{ HPL } & Actuate valves & 2 & $1.10 \mathrm{E}-03$ & $3.45 \mathrm{E}-04$ & $1.56 \mathrm{E}-04$ \\
\hline & HP pumps & 2 & $7.37 \mathrm{E}-02$ & $3.02 \mathrm{E}-02$ & $1.66 \mathrm{E}-02$ \\
\hline & Flange & 6 & $2.19 \mathrm{E}-04$ & $7.96 \mathrm{E}-05$ & $7.61 \mathrm{E}-05$ \\
\hline & Pipe & 3 & $2.85 \mathrm{E}-03$ & $1.00 \mathrm{E}-03$ & 4.65E-04 \\
\hline & $\begin{array}{l}\text { Small gauge } \\
\text { fittings }\end{array}$ & 3 & $9.32 \mathrm{E}-04$ & $4.08 \mathrm{E}-04$ & 2.59E-04 \\
\hline & \multicolumn{2}{|l|}{ Total } & $7.88 \mathrm{E}-02$ & $3.21 \mathrm{E}-02$ & $1.76 \mathrm{E}-02$ \\
\hline \multirow{6}{*}{ HPV } & Actuate valves & 1 & $5.48 \mathrm{E}-04$ & $1.72 \mathrm{E}-04$ & $7.80 \mathrm{E}-05$ \\
\hline & Flange & 6 & $2.19 \mathrm{E}-04$ & $7.96 \mathrm{E}-05$ & $7.61 \mathrm{E}-05$ \\
\hline & Heater & 1 & $1.64 \mathrm{E}-03$ & $7.71 \mathrm{E}-04$ & $6.26 \mathrm{E}-04$ \\
\hline & Pipe & 3 & $2.85 \mathrm{E}-03$ & $1.00 \mathrm{E}-03$ & $4.65 \mathrm{E}-04$ \\
\hline & $\begin{array}{l}\text { Small gauge } \\
\text { fittings }\end{array}$ & 1 & $3.11 \mathrm{E}-04$ & $1.36 \mathrm{E}-04$ & 8.64E-05 \\
\hline & \multicolumn{2}{|l|}{ Total } & $5.56 \mathrm{E}-03$ & $2.16 \mathrm{E}-03$ & $1.33 \mathrm{E}-03$ \\
\hline \multirow{8}{*}{ LPV } & Actuated valves & 4 & $2.19 \mathrm{E}-03$ & $6.89 \mathrm{E}-04$ & $3.12 \mathrm{E}-04$ \\
\hline & BOG compressor & 2 & 7.37E-02 & $3.02 \mathrm{E}-02$ & $1.66 \mathrm{E}-02$ \\
\hline & Flange & 16 & 5.85E-04 & $2.12 \mathrm{E}-04$ & $2.03 \mathrm{E}-04$ \\
\hline & Heater & 1 & $1.64 \mathrm{E}-03$ & $7.71 \mathrm{E}-04$ & $6.26 \mathrm{E}-04$ \\
\hline & Manual valves & 4 & $2.11 \mathrm{E}-04$ & $9.20 \mathrm{E}-05$ & $6.09 \mathrm{E}-05$ \\
\hline & Pipe & 20 & $1.90 \mathrm{E}-02$ & $6.69 \mathrm{E}-03$ & $3.10 \mathrm{E}-03$ \\
\hline & $\begin{array}{c}\text { Small gauge } \\
\text { fittings }\end{array}$ & 4 & $1.24 \mathrm{E}-03$ & $5.43 \mathrm{E}-04$ & $3.45 \mathrm{E}-04$ \\
\hline & \multicolumn{2}{|c|}{ Total } & $9.85 \mathrm{E}-02$ & $3.92 \mathrm{E}-02$ & $2.13 \mathrm{E}-02$ \\
\hline
\end{tabular}


Table 4 Reliability data for safety systems.

(ORADA, 2009; EPRI, 1995; Kletz, 1991; CCPS, 1989)

\begin{tabular}{lcccc}
\hline & & & & Unreliability \\
& $\begin{array}{c}\text { Safety System } \\
\text { List }\end{array}$ & $\lambda$ & Reliability R(t) & (1-R(t)) \\
\hline $\mathbf{1}$ & Gas detector & $3.67 \mathrm{E}-01$ & 0.6930 & 0.3070 \\
$\mathbf{2}$ & Alarm & $2.50 \mathrm{E}-04$ & 0.99975 & 0.00025 \\
\hline $\mathbf{3}$ & $\begin{array}{c}\text { Operator to obey } \\
\text { alarm }\end{array}$ & - & 0.97 & 0.03 \\
\hline $\mathbf{4}$ & Cut-off V/V & $1.86 \mathrm{E}-02$ & 0.9816 & 0.0184 \\
\hline $\mathbf{5}$ & $\begin{array}{c}\text { Motor-driven fan } \\
\end{array}$ & $2.16 \mathrm{E}-01$ & 0.805 & 0.195 \\
\hline $\mathbf{6}$ & $\begin{array}{c}\text { Change-over } \\
\text { system }\end{array}$ & $6.50 \mathrm{E}-03$ & 0.99352 & 0.00648 \\
\hline
\end{tabular}


Table 5 Probability of immediate ignition (DNV, 2013).

\begin{tabular}{ccc}
\hline \multicolumn{2}{c}{ Leak Rate (kg/s) } & $\begin{array}{c}\text { Probability of } \\
\text { Immediate Ignition }\end{array}$ \\
\hline Gas & Liquid & 0.0001 \\
\hline$<1$ & $<1.2$ & 0.001 \\
\hline $1-10$ & $1.2-25$ & 0.01 \\
\hline$>10$ & $>25$ & \\
\hline
\end{tabular}


Table 6 Probability of delayed ignition (OGP, 2010).

\begin{tabular}{|c|c|}
\hline \multicolumn{2}{|c|}{ Delayed Ignition Probability } \\
Leak \\
Rate(kg/s) \\
\hline $1.00 \mathrm{E}-01$ & $\begin{array}{c}\text { Ignition } \\
\text { Probability }\end{array}$ \\
\hline $2.00 \mathrm{E}-01$ & $1.00 \mathrm{E}-03$ \\
\hline $5.00 \mathrm{E}-01$ & $2.30 \mathrm{E}-03$ \\
\hline $1.00 \mathrm{E}+00$ & $6.60 \mathrm{E}-03$ \\
\hline $2.00 \mathrm{E}+00$ & $1.50 \mathrm{E}-02$ \\
\hline $5.00 \mathrm{E}+00$ & $1.74 \mathrm{E}-02$ \\
\hline $1.00 \mathrm{E}+01$ & $2.13 \mathrm{E}-02$ \\
\hline $2.00 \mathrm{E}+01$ & $2.47 \mathrm{E}-02$ \\
\hline $5.00 \mathrm{E}+01$ & $2.87 \mathrm{E}-02$ \\
\hline $1.00 \mathrm{E}+02$ & $3.50 \mathrm{E}-02$ \\
\hline $2.00 \mathrm{E}+02$ & $4.00 \mathrm{E}-02$ \\
\hline $5.00 \mathrm{E}+02$ & $4.00 \mathrm{E}-02$ \\
\hline $1.00 \mathrm{E}+03$ & $4.00 \mathrm{E}-02$ \\
\hline & $4.00 \mathrm{E}-02$ \\
\hline & \\
\hline & \\
\hline
\end{tabular}


Table 7 Model verification tests

\begin{tabular}{|c|c|c|c|c|c|}
\hline \multirow{2}{*}{ Case } & \multicolumn{2}{|c|}{ Scenario } & \multicolumn{2}{c|}{ Max. pressure } & \multirow{2}{*}{ Deviation } \\
\cline { 2 - 5 } & $\begin{array}{c}\text { Leak } \\
\text { Quantity }\end{array}$ & $\begin{array}{c}\text { Mass } \\
\text { Ratio } \\
\text { Fuel/Air }\end{array}$ & $\begin{array}{c}\text { FLACS } \\
\text { (Republic of } \\
\text { Korea, 2014) }\end{array}$ & STAR-CCM+ & \\
\hline Case 1 & $5.353 \mathrm{~kg}$ & $1: 32.3$ & 0.27 Bar & $0.3 \mathrm{Bar}$ & 0.03 Bar \\
\hline Case 2 & $41.0 \mathrm{~kg}$ & $1: 4$ & $3.7 \mathrm{Bar}$ & $3.71 \mathrm{Bar}$ & $0.01 \mathrm{Bar}$ \\
\hline
\end{tabular}


Table 8 CFD simulation conditions.

\begin{tabular}{|c|c|}
\hline Parameters & Value \\
\hline 2D Geometry & $3.0 \mathrm{~m} \times 2.5 \mathrm{~m}$ \\
\hline Number of mesh cells & 75,294 \\
\hline Initial temperature & $293 \mathrm{~K}$ \\
\hline Initial pressure & $101.3 \mathrm{kPa}$ \\
\hline $\begin{array}{c}\text { Mass fractions of } \mathbf{C H}_{4}, \mathbf{O}_{\mathbf{2}}, \mathbf{N}_{\mathbf{2}} \\
\text { (fuel-air ratio by mass } \mathbf{1 : 1 7 . 3 )}\end{array}$ & $0.0545,0.2203,0.7252$ \\
\hline
\end{tabular}


Table 9 Stiffened designs for each case.

\begin{tabular}{ccccc}
\hline & Case 1 & Case 2 & Case 3 & Case 4 \\
\hline $\begin{array}{c}\text { Primary } \\
\text { supporting } \\
\text { member }\end{array}$ & $500 \times 12+100 \times 15(\mathrm{~T})^{3}$ & $700 \times 12+100 \times 15(\mathrm{~T})$ & $900 \times 15+200 \times 18(\mathrm{~T})$ & $1,100 \times 15+200 \times 18(\mathrm{~T})$ \\
\hline $\begin{array}{c}\text { Secondary } \\
\text { member }\end{array}$ & $100 \times 75 \times 10 / 14 \mathrm{~A}$ & $200 \times 90 \times 10 / 14 \mathrm{~A}$ & $300 \times 90 \times 11 / 16 \mathrm{~A}$ & $400 \times 100 \times 13 / 18 \mathrm{~A}$ \\
\hline $\begin{array}{c}\text { Thickness of base } \\
\text { plate }\end{array}$ & $10 \mathrm{~mm}$ & $12 \mathrm{~mm}$ & $14 \mathrm{~mm}$ & $16 \mathrm{~mm}$ \\
\hline $\begin{array}{c}\text { Total number of } \\
\text { elements }\end{array}$ & 56,080 & 62,760 & 68,760 & 77,080 \\
(for simulation) & & & & \\
\hline
\end{tabular}

${ }^{3}$ (web depth $\mathrm{x}$ web thickness + face plate breadth $\mathrm{x}$ face plate thickness)

4 (web depth $\mathrm{x}$ flange breadth $\mathrm{x}$ web thickness/flange thickness) 
Table 10 Result of ETA for various cases.

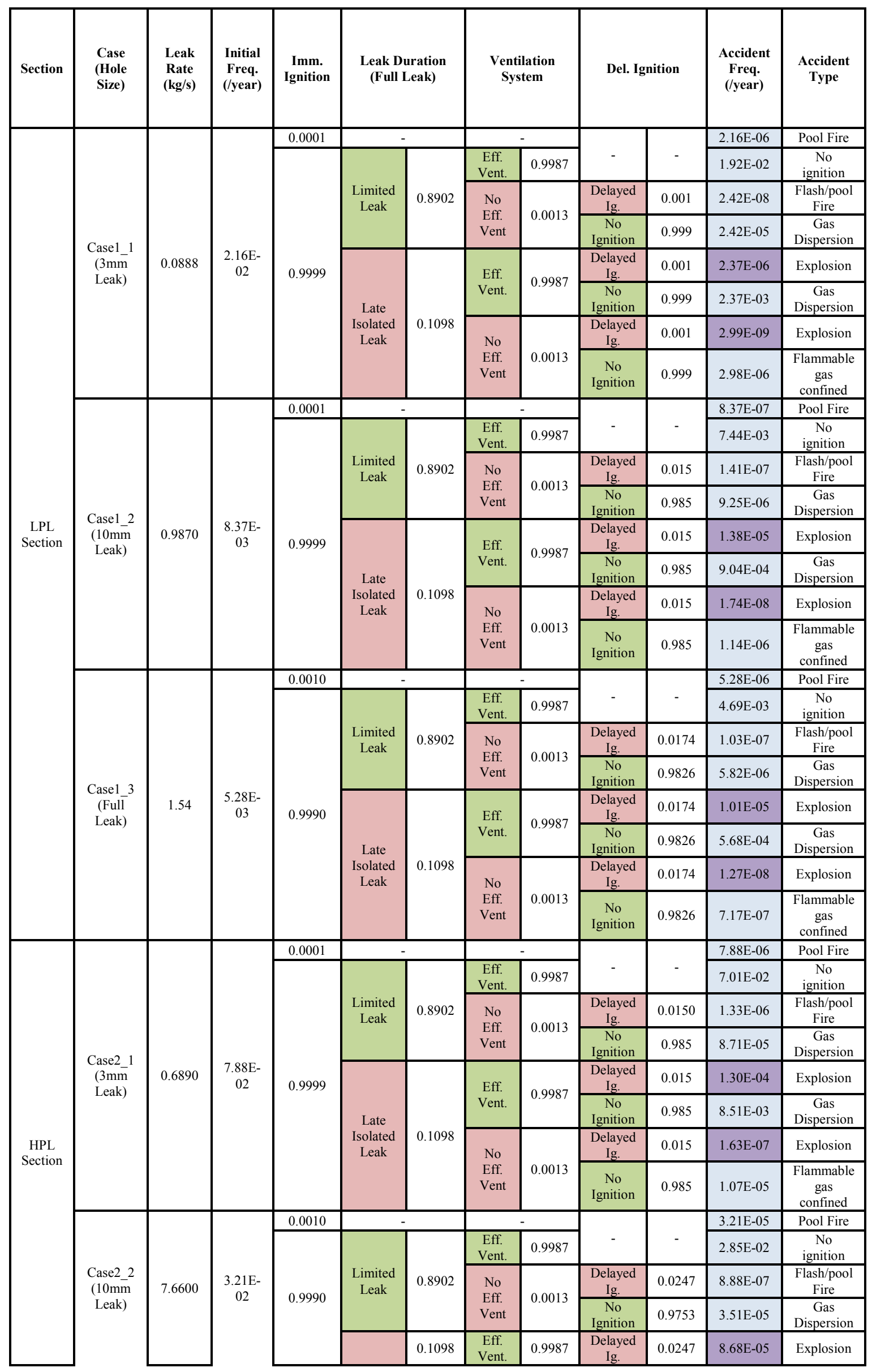




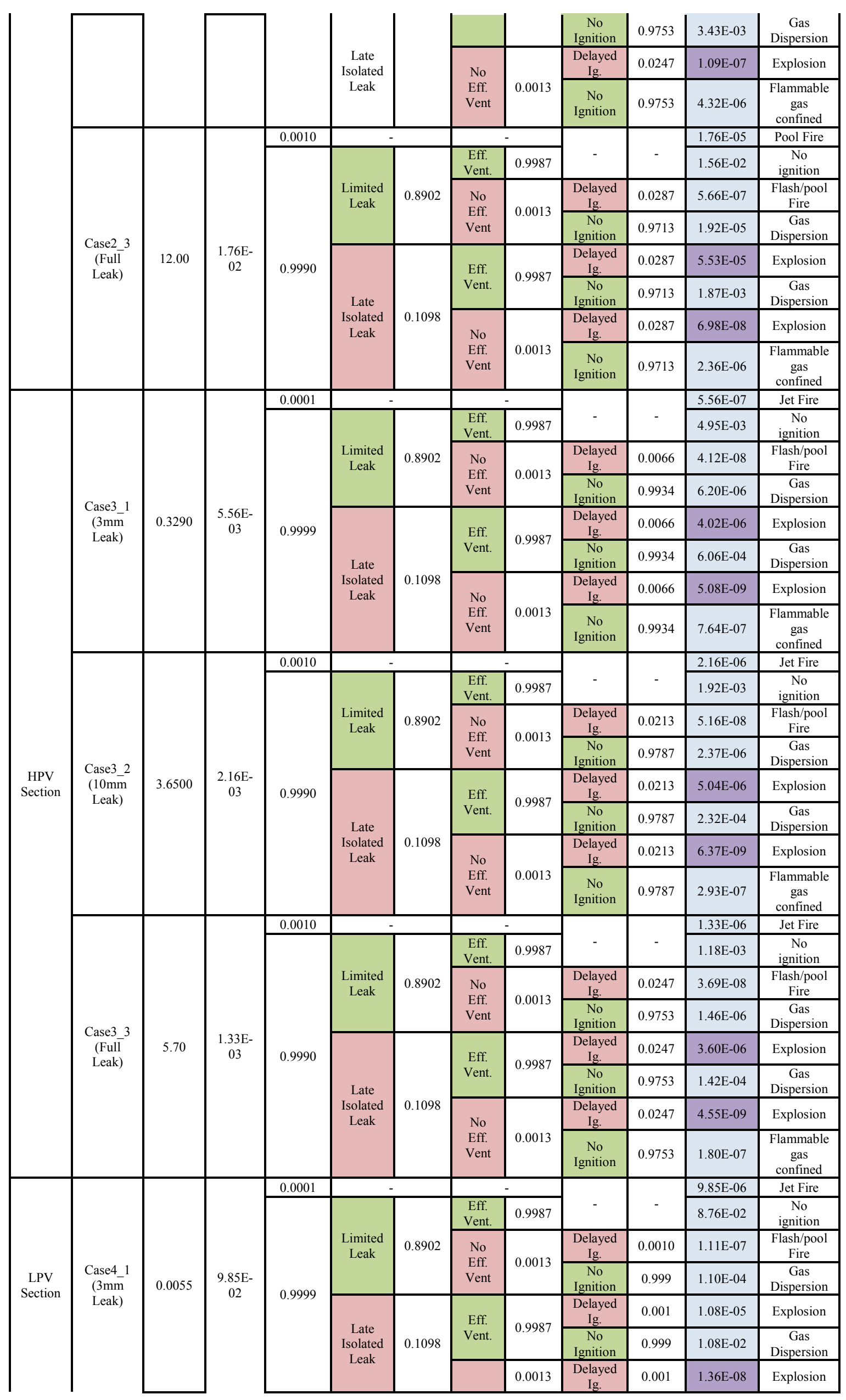




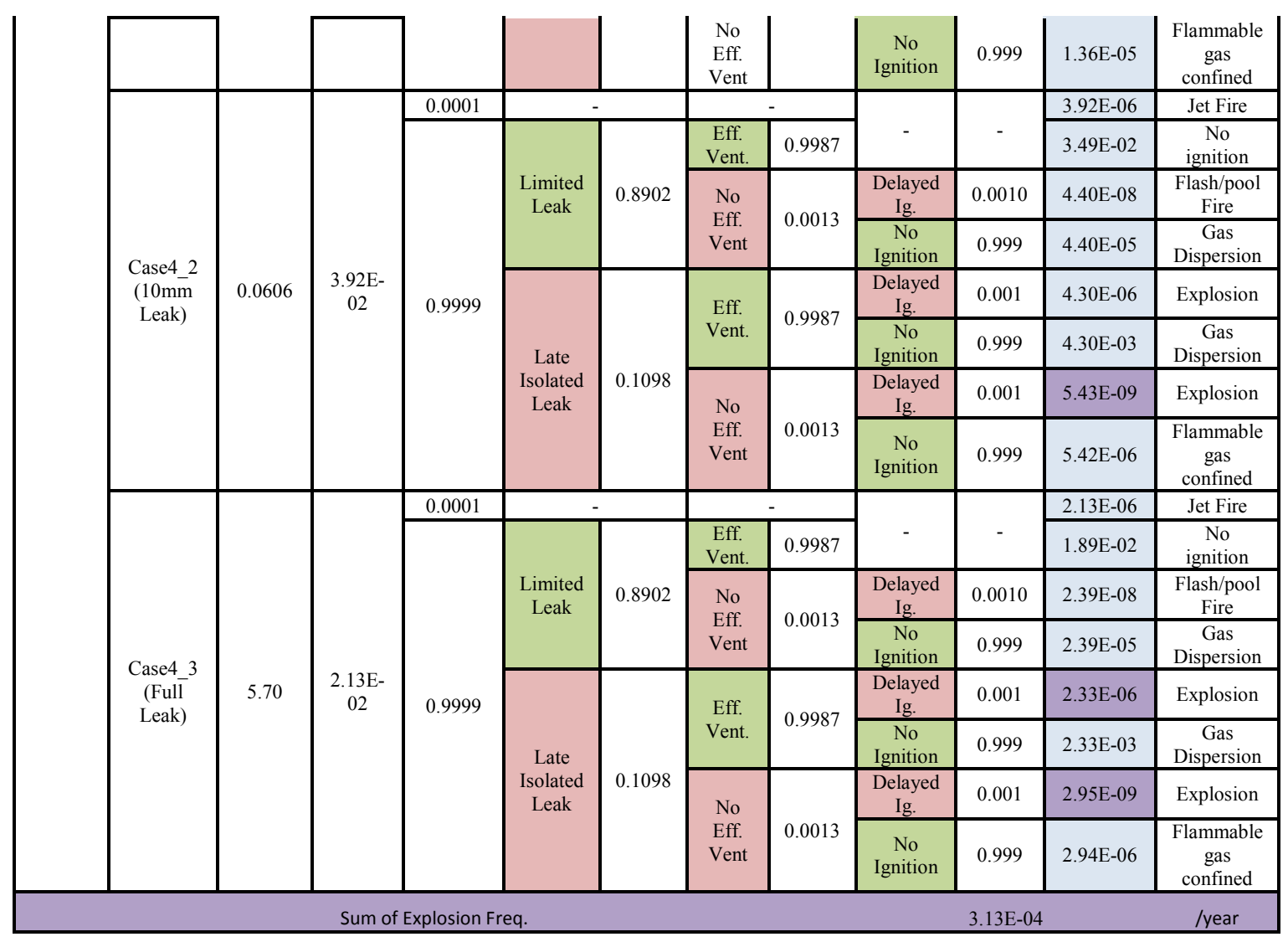


Table 11 Summary of stresses for various scantlings.

\begin{tabular}{|c|r|r|r|r|r|}
\hline \multirow{2}{*}{$\begin{array}{c}\text { Type of } \\
\text { Stress }\end{array}$} & \multirow{2}{*}{$\begin{array}{c}\text { Allowable } \\
\text { Stress } \\
\left(\mathrm{N} / \mathrm{mm}^{2}\right)\end{array}$} & \multicolumn{3}{|c|}{ Maximum Actual Stress $\left(\mathrm{N} / \mathrm{mm}^{2}\right)$} \\
\cline { 3 - 6 } & 90.0 & 259.7 & 137.5 & 89.6 & 58.6 \\
\hline Shear stress & 160.0 & 1170.0 & 440.1 & 243.2 & 143.1 \\
\hline Bending stress & 245.0 & 1250.0 & 505.1 & 283.6 & 213.4 \\
\hline $\begin{array}{c}\text { Equivalent } \\
\text { stress }\end{array}$ & & & & Case 3 & Case 4 \\
\hline
\end{tabular}


Table 12 Summary of stresses associated with alternative scenarios for various scantlings.

\begin{tabular}{|c|c|c|c|c|c|c|c|}
\hline \multirow{2}{*}{ Stress Type } & \multirow{2}{*}{$\begin{array}{l}\text { Allowab } \\
\text { le Stress } \\
\left(\mathrm{N} / \mathrm{mm}^{2}\right)\end{array}$} & \multirow{2}{*}{$\begin{array}{c}\text { Methan } \\
\text { e-Air } \\
\text { Ratio }\end{array}$} & \multirow{2}{*}{$\begin{array}{l}\text { Ignition Point } \\
\text { (vertical } \\
\text { distance from } \\
\text { floor) }\end{array}$} & \multicolumn{4}{|c|}{ Maximum Actual Stress (N/mm²) } \\
\hline & & & & Case 1 & Case 2 & Case 3 & Case 4 \\
\hline \multirow{9}{*}{ Shear Stress } & \multirow{9}{*}{90} & \multirow{3}{*}{$5 \%$} & $0.7 \mathrm{~m}$ & 214.2 & 120.8 & 80.6 & 57.6 \\
\hline & & & $0.9 \mathrm{~m}$ & 174.4 & 97.1 & 64.6 & 46.1 \\
\hline & & & $1 \mathrm{~m}$ & 156.8 & 87.1 & 57.9 & 41.3 \\
\hline & & \multirow{3}{*}{$10 \%$} & $0.7 \mathrm{~m}$ & 339.3 & 194.9 & 130.6 & 93.9 \\
\hline & & & $0.9 \mathrm{~m}$ & 267.6 & 150.9 & 100.6 & 72.0 \\
\hline & & & $1 \mathrm{~m}$ & 259.7 & 137.5 & 89.6 & 58.6 \\
\hline & & \multirow{3}{*}{$15 \%$} & $0.7 \mathrm{~m}$ & 326.2 & 186.9 & 125.1 & 90.0 \\
\hline & & & $0.9 \mathrm{~m}$ & 259.7 & 146.3 & 97.5 & 69.8 \\
\hline & & & $1 \mathrm{~m}$ & 230.7 & 129.3 & 86.1 & 61.6 \\
\hline \multirow{9}{*}{$\begin{array}{l}\text { Bending } \\
\text { Stress }\end{array}$} & \multirow{9}{*}{160} & \multirow{3}{*}{$5 \%$} & $0.7 \mathrm{~m}$ & 1000.0 & 376.0 & 213.8 & 141.9 \\
\hline & & & $0.9 \mathrm{~m}$ & 785.2 & 292.7 & 167.3 & 111.0 \\
\hline & & & $1 \mathrm{~m}$ & 695.6 & 259.7 & 149.1 & 98.9 \\
\hline & & \multirow{3}{*}{$10 \%$} & $0.7 \mathrm{~m}$ & 1680.0 & 634.5 & 360.9 & 239.7 \\
\hline & & & $0.9 \mathrm{~m}$ & 1250.0 & 468.9 & 267.1 & 177.2 \\
\hline & & & $1 \mathrm{~m}$ & 1170.0 & 440.1 & 243.2 & 143.1 \\
\hline & & \multirow{3}{*}{$15 \%$} & $0.7 \mathrm{~m}$ & 1600.0 & 605.0 & 344.1 & 288.5 \\
\hline & & & $0.9 \mathrm{~m}$ & 1121.0 & 453.6 & 258.4 & 171.5 \\
\hline & & & $1 \mathrm{~m}$ & 1060.0 & 395.1 & 225.9 & 149.8 \\
\hline \multirow{9}{*}{$\begin{array}{l}\text { Equivalent } \\
\text { Stress }\end{array}$} & \multirow{9}{*}{245} & \multirow{3}{*}{$5 \%$} & $0.7 \mathrm{~m}$ & 1070.0 & 400.5 & 227.7 & 200.0 \\
\hline & & & $0.9 \mathrm{~m}$ & 833.1 & 376.1 & 213.7 & 151.5 \\
\hline & & & $1 \mathrm{~m}$ & 738.1 & 361.2 & 205.3 & 134.3 \\
\hline & & \multirow{3}{*}{$10 \%$} & $0.7 \mathrm{~m}$ & 1780.0 & 666.6 & 373.0 & 352.9 \\
\hline & & & $0.9 \mathrm{~m}$ & 1330.0 & 517.8 & 294.3 & 248.9 \\
\hline & & & $1 \mathrm{~m}$ & 1250.0 & 505.1 & 283.6 & 213.4 \\
\hline & & \multirow{3}{*}{$15 \%$} & $0.7 \mathrm{~m}$ & 1700.0 & 635.6 & 355.5 & 334.5 \\
\hline & & & $0.9 \mathrm{~m}$ & 1129.0 & 507.2 & 288.3 & 240.4 \\
\hline & & & $1 \mathrm{~m}$ & 1120.0 & 485.5 & 275.9 & 207.3 \\
\hline
\end{tabular}

